\title{
Studying Alzheimer disease, Parkinson disease, and amyotrophic lateral sclerosis with 7-T magnetic resonance
}

\author{
Emrah Düzel ${ }^{1,2,3^{*}}$, Mauro Costagli $i^{4,5}$, Graziella Donatelli, ${ }^{6,7}$, Oliver Speck ${ }^{1,2}$ and Mirco Cosottini ${ }^{7,8}$
}

\begin{abstract}
Ultra-high-field (UHF) magnetic resonance (MR) scanners, that is, equipment operating at static magnetic field of 7 tesla (7 T) and above, enable the acquisition of data with greatly improved signal-to-noise ratio with respect to conventional MR systems (e.g., scanners operating at $1.5 \mathrm{~T}$ and $3 \mathrm{~T}$ ). The change in tissue relaxation times at UHF offers the opportunity to improve tissue contrast and depict features that were previously inaccessible. These potential advantages come, however, at a cost: in the majority of UHF-MR clinical protocols, potential drawbacks may include signal inhomogeneity, geometrical distortions, artifacts introduced by patient respiration, cardiac cycle, and motion. This article reviews the 7 T MR literature reporting the recent studies on the most widespread neurodegenerative diseases: Alzheimer's disease, Parkinson's disease, and amyotrophic lateral sclerosis.
\end{abstract}

Keywords: Alzheimer disease, Amyotrophic lateral sclerosis, Magnetic resonance imaging, Neurodegenerative diseases, Parkinson disease

\section{Key points}

- Ultra-high-field MRI enables improved signal-tonoise ratio, resolution and tissue contrast.

- In Alzheimer disease, 7-T MRI enables highresolution assessment of neurodegenerative processes affecting hippocampal structures as well as vascular lesions and vascular reserve.

- $7 \mathrm{~T}$ imaging of substantia nigra has outstanding accuracy in identifying Parkinson disease patients.

- In Amyotrophic lateral sclerosis, 7-T MRI reveals motor neuron impairment signs in cerebral cortex.

\footnotetext{
* Correspondence: emrah.duezel@dzne.de

This article belongs to the thematic series entitled "7-tesla neuro MRI: from research to clinic" (Guest Editors Prof. Luca Roccatagliata (Genoa/Italy) and Mirco Cosottini (Pisa/ltaly)).

'Otto-von-Guericke University Magdeburg, Magdeburg, Germany

${ }^{2}$ German Center for Neurodegenerative Diseases (DZNE), Magdeburg, Germany

${ }^{3}$ University College London, London, UK

Full list of author information is available at the end of the article
}

\section{Introduction}

Magnetic resonance (MR) is used in medicine since nearly four decades ago. While its ability to represent soft tissues in vivo non-invasively has had a crucial impact on clinical diagnosis since its early days, the steady quest for improved data quality and signal-to-noise ratio (SNR) has led to the recent use, in clinical studies, of MR scanners operating at ultra-high field (UHF) of $7 \mathrm{~T}$ and beyond.

In imaging (MRI) applications, the main advantage of higher SNR is the increased sensitivity to signal changes related to tissue composition and physiological parameters [1]. The higher SNR, which increases linearly with the static magnetic field strength, enables also to achieve improved spatial resolution. Another important feature in UHF MR is the change in tissue relaxation times: in particular, the combination of higher SNR and shorter $\mathrm{T}^{*}$ a at UHF has been exploited to obtain images with unprecedented anatomical detail in susceptibilityweighted imaging (SWI) and quantitative susceptibility mapping (QSM) [2]. In functional MRI (fMRI), these 
two features have enabled researchers to obtain activation maps based on blood oxygenation level dependent (BOLD) contrast with sub-millimetric resolution [3, 4]. Such an increased sensitivity to magnetic susceptibility is, however, also a source of undesired effects, primarily signal loss at tissue interfaces [5], vulnerability to artifacts introduced by patient respiration and cardiac cycle [6], motion [7], and geometrical distortions [8]. Techniques to mitigate these effects have not yet been implemented in the majority of clinical scenarios.

Another challenge in UHF MRI is posed by the shortening of the resonance wavelength at UHF, which can cause signal inhomogeneity at spatial scales of the size of the human head. This problem has been solved with parallel transmission [9] at a number of UHF MR sites; however, this technology is not yet available in the most part of clinical contexts.

In MR spectroscopy (MRS), besides the increase in SNR, one main advantage of operating at UHF is the increase in spectral resolution [10]. Further, as the resonance frequency increases linearly with the static magnetic field, operating at UHF also facilitates MRI and MRS of other nuclei, such as ${ }^{23} \mathrm{Na}$ and ${ }^{31} \mathrm{P}$, whose abundance (hence, MR signal) and resonance frequencies are far lower than those of the ${ }^{1} \mathrm{H}$ proton. In this context of intertwined potential advantages and challenges, this article aims to provide an overview of recent results and future perspective of UHF MR in clinical studies addressing three major neurodegenerative diseases, namely Alzheimer's diseases, Parkinson's disease, and amyotrophic lateral sclerosis.

\section{Alzheimer disease}

Alzheimer disease (AD) is characterized by long preclinical and prodromal stages with progressive molecular pathology, neurodegeneration and cognitive impairment. The ATN (amyloid, Tau, neurodegeneration) [11] research framework considers ß-Amyloid, Tau-pathology, and neurodegeneration (neuronal or synaptic loss, atrophy) as the hallmarks of clinical diagnosis and individual staging for the purpose of clinical trials. While the levels of $\beta$-amyloid and taupathology can be determined using cerebro-spinal fluid (CSF), plasma, and molecular imaging methods [12], determining the degree of neurodegeneration (as defined in the ATN framework) remains challenging and 7-T magnetic resonance imaging could provide a substantial advantage over MRI at 1.5 or $3 \mathrm{~T}$. In addition to assessing neurodegeneration, 7-T imaging provides innovative readouts for vascular pathology occurring either as a consequence of $\mathrm{AD}$ or as a comorbidity, for dysfunction of macro- and mesoscale neural networks and for molecular pathology.

\section{Assessment of neurodegeneration in $A D$}

Measures of cortical and subcortical grey matter volume or thickness with MRI and their progression over time are likely to be the most direct measures of local neurodegeneration that are currently available. Structural MRI with visual inspection at 1.5 and $3 \mathrm{~T}$ has been at the heart of diagnostic radiology in dementia for two decades, while volumetric analysis from structural imaging has been the principal imaging marker of major cohort studies and trials of disease modifying therapies in symptomatic sporadic dementia with approval by the European Medicines Agency [13, 14] and pre-symptomatic genetic dementias [15]. Structural sequences have proven sufficiently robust to site and even manufacturer effects, to allow large scale multi-center collaborative studies. Following this widespread use, there is extensive modelling and empirical evidence for the power of T1and T2-weighted imaging to detect rates of change and the effect of treatment, for a given cohort size, study duration, and drug effect [16]. $3 \mathrm{~T}$ structural MRI has become an industry standard surrogate marker for drug trials in Alzheimer's disease. However, $1.5 \mathrm{~T}$ and $3 \mathrm{~T}$ structural imaging is fundamentally limited by its coarse resolution (typically about $1 \mathrm{~mm}$; macro-scale) and contrast-to-noise ratio (SNR), which prevents accurate quantification of volumetric change within shortintervals or pre-symptomatic change, and accurate delineation of medial temporal sub-region and hippocampal subfield changes that characterize early stage neuropathology. This has been highlighted recently outlining the inadequacy of the common use of 3T-based $1 \mathrm{~mm}$ isotropic MRI to perform hippocampal subfield segmentations [17] using automated or manual methods. Given that cortical thickness is around $2-3 \mathrm{~mm}$, the limited sensitivity of current structural imaging to detect cortical atrophy is apparent. Efforts are underway to harness the superior resolution of $7 \mathrm{~T}$ for $\mathrm{AD}$ research. Examples for high-resolution structural imaging scans that have been successfully implemented in multi-center studies and across vendors, e.g., in the setting of the EUFIND (European ultra-high-field imaging network for neurodegenerative diseases) consortium, include a T1-weighted magnetization-prepared rapid gradient echo sequence for whole-brain anatomy (3D MPRAGE, $0.65-\mathrm{mm}$ isotropic resolution), and a T2-weighted acquisition centered on the medial temporal lobe (2D Turbo-Spin Echo, $0.4 \times 0.4 \times 1.0 \mathrm{~mm}$ resolution, orthogonal to the hippocampus' longest axis) [18]. As illustrated in recently developed 7-T segmentation protocols for the medial temporal lobe (MTL) [19], certain key landmarks that are difficult to identify at 3T, such as the endfolial pathway distinguishing dentate gyrus from hippocampal subfield CA3, can be identified reliably in 7-T scans using these types of resolution (Fig. 1). Other structures 


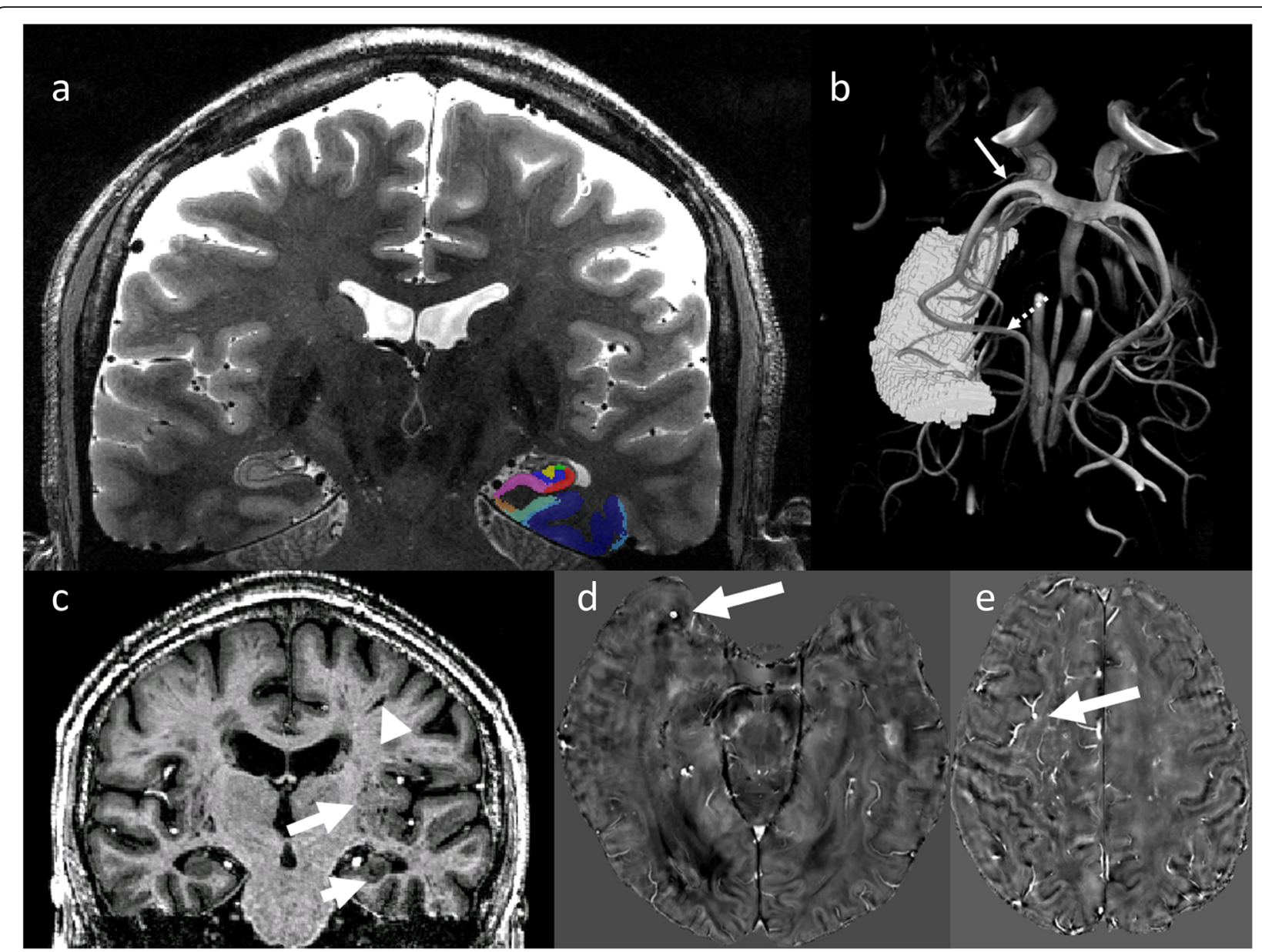

Fig. 1 Structural and vascular hippocampal and medial temporal lobe imaging at 7T in an older adult. a T2-weighted coronal 7-T MRI scan through the body of the hippocampus, immediately distal to the hippocampal head. Color legend of segmented regions: entorhinal cortex brown, Brodmann area 35 (transentorhinal) teal, Brodmann area 36 dark blue, subiculum mauve, CA1 red, CA2 green, CA3 yellow, dentate gyrus blue. $\mathbf{b}$ High-resolution time of flight imaging of hippocampal vascularization allowing to identify supplying vessels from the anterior choroidal artery (solid arrow) and the posterior cerebral artery (dashed arrow). c A structural T1-weighted coronal 7-T MRI in a patient with mild cognitive impairment and markedly enlarged perivascular spaces, particularly in the insular regions (long arrow) but also in the hippocampus (middle arrow). The scan also shows linear perivascular spaces alongside vessels (short arrow). $\mathbf{d}$ A microbleed in the anterior temporal lobe (white arrow) in a patient with cerebral amyloid angiopathy imaged with QSM at 7T. e A microbleed with a venous connection, as visualized with a QSM based venography

for which morphometric quantification of volume or thickness is difficult at $3 \mathrm{~T}$ include subregions of the entorhinal cortex $[20,21]$ and the transentorhinal cortex, which are affected early on in the pathological cascade of AD [12, 22-24]. These initial efforts revealed two acquisition problems, namely excessive head motion and signal loss in the inferior temporal lobe on T2-weighted scans. Future solutions could include prospective motion correction [25] and utilization of parallel transmission to homogenize the transmit field [9] and these solutions are indeed likely to be commercially available in foreseeable time.

While the benefits of $7 \mathrm{~T}$ for assessing cortical and subcortical morphometry at the macro-scale are ready- to-use for studies in $\mathrm{AD}$, the high-resolution of $7 \mathrm{~T}$ could also provide new, more mechanistic insights into how neurodegeneration progresses across brain regions by allowing to quantify structural integrity in different cortical layers by way of its submillimeter (meso-scale) resolution. Such quantification of laminar thickness and its changes in disease and with age and disease pathology [26, 27] can reveal microstructural insights into the causal cascade of neurodegeneration because of the layer-specific organization of feedforward and feedback connectivity [28].

Another emerging area of advanced structural imaging at $7 \mathrm{~T}$ that is relevant for $\mathrm{AD}$ is imaging of the locus coeruleus (LC). The LC is the sole origin of cerebral 
noradrenergic supply, and one of the first sites of the human brain to develop neurofibrillary tangles in preclinical AD (for a review see [29]). Studies at $3 \mathrm{~T}$ have already showed that the LC MRI contrast is reduced in $\mathrm{AD}$ in proportion to CSF $\mathrm{A} \beta$ levels [30]. Given the small size of the LC and its limited contrast, efforts are made to image its structural and functional integrity at $7 \mathrm{~T}$ [29] for instance by developing optimized magnetization transfer (MT)-weighted imaging approaches (e.g., [31]).

\section{Vascular system and vascular pathology}

Vascular pathology is an important risk factor and comorbidity that can modify neurodegeneration and disease progression in $\mathrm{AD}$ [11]. While it can be associated with neurodegeneration even in the absence of Alzheimer's disease pathology [32, 33], it is now clear that there is an interaction between vascular and nonvascular pathology in AD. Indeed, vascular pathology has been proposed as an important driver of neurodegeneration for amyloid-positive but tau-negative individuals [11]. Besides established markers of small vessel disease (SVD) at $3 \mathrm{~T}$ (white matter hyperintensities, lacunes, microbleeds [34,35], perivascular spaces), ultrahigh-resolution imaging offers new possibilities to quantify vascular pathology and vascular reserve. Corresponding ultra-high-resolution sequences have been implemented in multi-center networks such as EUFIND. Measures technically feasible at $7 \mathrm{~T}$ include FluidAttenuated Inversion Recovery (FLAIR), T2 and T1 to image white matter hyperintensities, microinfarcts (hyperintense on FLAIR and hypointense on T1 MPRAGE) $[36,37]$, perivascular spaces, diffusion tensor imaging (DTI) to infer information about axonal integrity in the vicinity of white matter hyperintensities, ultra-highresolution $2 \mathrm{D}$ phase-contrast imaging to assess the pulsatility of perforating arteries [37-42], QSM to image microbleeds (spherical hypointensities on the magnitude images of the QSM datasets) [34, 35], venous vessel density, length, tortuosity and branching patterns, and time-of-flight (TOF) angiography to measure small arterial features including the hippocampal small-vessel vascularization patterns $[43,44]$.

Enlarged perivascular spaces (Fig. 1c), which are enlarged pathways of clear interstitial fluid, while still unclear whether they represent perivenular or periarteriolar phenomena [45], are likely to indicate a failure to clear fluid and waste, including amyloid and tau protein [46-48]. Combinations of FLAIR, T2weighted, and susceptibility-weighted imaging submillimeter resolution venography and TOF angiography with high resolution at $7 \mathrm{~T}[49,50]$ could provide new insights into pathological progression of vascular dysfunction in $\mathrm{AD}$ and the interaction between small vessel disease and $\mathrm{AD}$. For instance, high-resolution 7-T assessments of the progressive build-up of perivascular spaces alongside the temporal progression of amyloid and tau pathology could indicate whether dysfunction in clearance precedes the progression of amyloid and tau pathology or is a consequence of its progression (i.e., more waste products to clear). Furthermore, in combination with structural imaging of cortical neurodegeneration (see above), $7 \mathrm{~T}$ could help to assess individually whether progression of neurodegeneration is related primarily to AD pathology (amyloid and tau) or concomitant vascular disease. A quantitative vascular profile including white matter hyperintensity volume, number of microinfacts, number of microbleeds (Fig. 1d), mean length and tortuosity of arteries and veins, mean venous density, number of perforating arteries, mean perforating artery velocity and mean perforating artery pulsatility index, perivascular spaces, and their spatial distribution, could be assessed and related to neurodegeneration and the progression of amyloid and tau pathology. Given the superior resolution of $7 \mathrm{~T}$, it can be expected to assess this prognostic question with higher sensitivity and in a shorter time period than with $3 \mathrm{~T}$, but this needs to be demonstrated in comparative studies. Given the advent of disease modifying treatments targeting amyloidpathology, such individualized assessments of the cause of neurodegeneration could have important impact for therapeutic decisions in a personalized medicine framework. Finally, a clinically important question to which this type of multimodal imaging could contribute is the differential diagnosis of small vessel disease and cerebral amyloid angiopathy (Fig. 1e).

Recently, it has been shown that 7-T high-resolution TOF-angiography enables to classify individual hippocampal vascularization patterns [43, 44]. Five hippocampal vascularization patterns can be distinguished, according to the origin of the hippocampal arteries. We have shown that the 7T-based in-vivo classification yields similar results as former post-mortem studies and that individuals whose hippocampus is supplied by one vessel system (posterior cerebral artery) as opposed to two systems (also anterior choroidal artery) and have cerebral small vessel disease, have poorer cognitive scores [43]. Hence, $7 \mathrm{~T}$ may provide a window to individually assess hippocampal vascular reserve and thus opens new perspectives for personalized risk modification and disease management. In this context, the interaction between vascular reserve and progression of Alzheimer's disease could also be particularly relevant. It can be hypothesized that individuals with lower hippocampal vascular reserve as determined on the basis of hippocampal vascular supply patterns, could suffer steeper cognitive decline (fast progressor) with advancing amyloid and tau pathology. 


\section{Functional imaging}

While synapse loss correlates closely with symptoms in Alzheimer's disease [51] and therefore neurodegeneration is an important target of MRI imaging, it is also well established that amyloid and tau-pathology can impair brain function through synaptotoxicity. Animal studies show that misfolded and hyperphosphorylated tau can impair neuronal function [52]. Mislocation of tau to dendritic spines can cause synaptic dysfunction [53] and there is evidence that pathological tau reduces network activity [54]. This is well compatible with the reduction of a novelty response in the hippocampus and amygdala as recently reported to be independent of hippocampal and amygdala MRI volume [55]. It is also well established that $A ß$ oligomer species are neurotoxic and cause synaptic dysfunction [56, 57]. A recent study indicated that the earliest accumulation of $A ß$ oligomers reduces the resting state connectivity of the precuneus [58].

The main advantages of higher field strength for functional MRI (fMRI) are the increased nuclear magnetization and susceptibility effects, leading to increased blood oxygenation level dependent (BOLD) contrast $[59,60]$ and therefore $7-\mathrm{T}$ fMRI can provide up to 30 times higher spatial resolution than fMRI at $3 \mathrm{~T}$ and allow to gain new insights into brain dysfunction in $\mathrm{AD}$. Of particular interest in AD is the dysfunction in hippocampal circuits. Currently, it is still unclear whether hippocampal dysfunction is related to the progression of tau- or amyloid-pathology or is related more to neurodegeneration (synaptic loss). This is an important question, because neurodegeneration-independent dysfunction is potentially reversible with treatments targeting tau- or amyloid-pathology. According to this possibility, circuitspecific dysfunction is the first impact of tau- and/or amyloid-pathology which is then followed by neurodegeneration. Currently, due to the limited resolution of 3 $\mathrm{T}$, this question cannot be advanced much beyond what is already known. 7-T imaging, by enabling more sensitive measures of atrophy and brain function, can help to gain new insights into the question how neurodegeneration and/or synaptic dysfunction contribute to cognitive deficits and clinical disease progression.

Amyloid pathology can also be associated with intrinsic neuronal hyperexcitability of pyramidal neurons, which is already detectable at pre-plaque stages [61]. It is paralleled by inhibitory dysfunction which is thought to underlie the generation of network hyperexcitability and hypersynchrony that is observed in neurocognitive circuits of patients and of disease models [62]. Although fMRI studies are compatible with the presence of hyperactivity in preclinical and prodromal $A D$, thus far it could not be established whether increases in hippocampal activity reflect intrinsic hyperactivity or are rather a compensatory upregulation of activity in some subfields.
$7 \mathrm{~T}$ based assessment of subfield-connectivity profiles could provide new insights into these questions.

The combination of ultra-high-resolution structural and functional imaging may be particularly powerful by allowing to assess the function of local circuits that are affected early by neurodegeneration and by allowing to quantify neurodegeneration precisely (Fig. 1). In the preclinical course of Alzheimer's disease, tau-pathology spreads from perirhinal and entorhinal subregions to hippocampal subfields and amygdala and later to lateral temporal, frontal, and midline parietal regions [22, 63]. Therefore, 7T-based tools to assess the detailed functional connectivity profile of the hippocampus, its subfields and of the perirhinal and subregions of the entorhinal cortices in preclinical AD are expected to be highly valuable.

\section{Iron mapping}

Iron dysregulation is thought to play a significant role in the pathogenesis of neurodegenerative diseases such as Alzheimer's disease [64], Parkinson's disease [65], and amyotrophic lateral sclerosis [66]. Large numbers of ironladen glial cells are commonly found in the vicinity of pathological aggregates in these disorders [67-70]. QSM [71] and apparent transverse relaxation rate (R2*) - both related to brain iron levels in vivo-revealed differential patterns of involvement in aging [72-76] and Alzheimer's disease [77-79]. QSM studies at $7 \mathrm{~T}$ may provide new insights into the role of iron-deposition in the pathophysiology of AD. In addition, QSM can help imaging venous vessels and their role in clearance of interstitial fluid and toxic waste and thus provide complementary information to TOF imaging of the arterial system. Finally, microbleeds can be well imaged with susceptibility-weighted imaging (see above) and imaging them may play an important role in the stratification for and monitoring of amyloid-modifying treatments where edema and microbleeds are major complications [80-84].

\section{Parkinson disease}

Parkinson disease (PD) is a disabling neurodegenerative disorder, characterized clinically by motor and nonmotor symptoms, and pathologically by synuclein intracellular inclusions with Lewy bodies formation.

Disease progression is characterized by the loss of dopaminergic neurons, the decreasing of neuromelanin content and the accumulation of iron in the substantia nigra (SN). The SN has been studied as the target of PD pathology with MR imaging since several decades; however, conventional MR sequences [85], segmented inversion-recovery ratio imaging [86] as well as DTI [87-89] did not enable the definition of the normal anatomy of the $\mathrm{SN}$ and have a limited role in diagnosing PD in individual subjects $[90,91]$. 
Ultra-high-field (UHF) MRI offers several advantages for studying brainstem nuclei by enabling the assessment of their neuroanatomy and neurophysiology [92]. In particular, since magnetic susceptibility effects and signal phase tissue contrast increase with the static magnetic field (B0), higher contrast-to-noise ratio is achieved in susceptibility-weighted imaging at UHF. Moreover, the increase in signal-to-noise ratio (SNR) [93] can be spent to improve the spatial resolution in small brain structures such as the midbrain $[92,94]$. With these premises, the introduction of 7-T MR equipment gave a new impulse to the imaging investigation of patients affected by PD: until the advent of 7-T MR, the evaluation of the substantia nigra, its inner structure, and its pathological changes in PD remained a prerogative of nuclear medicine, and neuroradiologic techniques were limited to the differential diagnosis.

\section{Iron sensitive 7-T MR of the substantia nigra}

7-T MR has been used in PD to identify a radiological surrogate marker of nigral pathology to increase the diagnostic accuracy with respect to conventional MR systems.

7-T MR imaging of the midbrain ex vivo and in vivo allows to depict the borders of the $\mathrm{SN}$ and its inner organization [95-97]. Iron-sensitive imaging sequences at $7 \mathrm{~T}$ targeting the midbrain demonstrated that the $\mathrm{SN}$ is structured into three tiers of signal intensity along the dorsoventral axis. From back to front, susceptibilityweighted images of the SN exhibit a thin hypointense signal band, followed by a high signal structure, which appears oval at the upper level, and, more anteriorly, by a large band of signal hypointensity extending until the crus cerebri (Fig. 2). The hyperintense ovoid area in the dorsolateral area of $\mathrm{SN}$ has been demonstrated to correspond to the largest nigrosome (nigrosome 1) [96] pertaining to calbindin-negative structures containing the neuromelanin of dopaminergic neurons and a low level of iron [98]. The nigrosome 1 has been variably described at $7 \mathrm{~T}[95,97,99]$ and finally the normal appearance of SN has been summarized with the term "swallow tail sign" [100] also at $7 \mathrm{~T}$ [101]. In PD, the nigrosome 1 is the most severely affected region of the SN [102]. The loss of signal hyperintensity of nigrosome 1 in PD is age-independent [103] and related to the loss of melanized neurons and to the increase of iron deposition [104] that, enhancing the magnetic susceptibility phenomena, masks the nigrosomal compartmental pattern based on calbindin of the SN [105]. The nigrosome 1 identification in healthy subjects [101] and its disappearance in PD has an outstanding diagnostic accuracy (sensitivity and specificity are respectively $100 \%$, 92.3-100\% [95]). Although MR signs of nigrosome 1 degeneration have been identified also at $3 \mathrm{~T}[100,106]$ and are accepted in the clinical practice for diagnosing PD [107], in comparative studies the diagnostic accuracy at $3 \mathrm{~T}$ was about $10 \%$ lower than that at $7 \mathrm{~T}$ [108].

Ferric iron rich (paramagnetic) brain tissues can be conveniently studied with susceptibility-weighted imaging (SWI), an MRI technique that uses the information of both signal magnitude and phase. The information embedded in phase data can also be used to

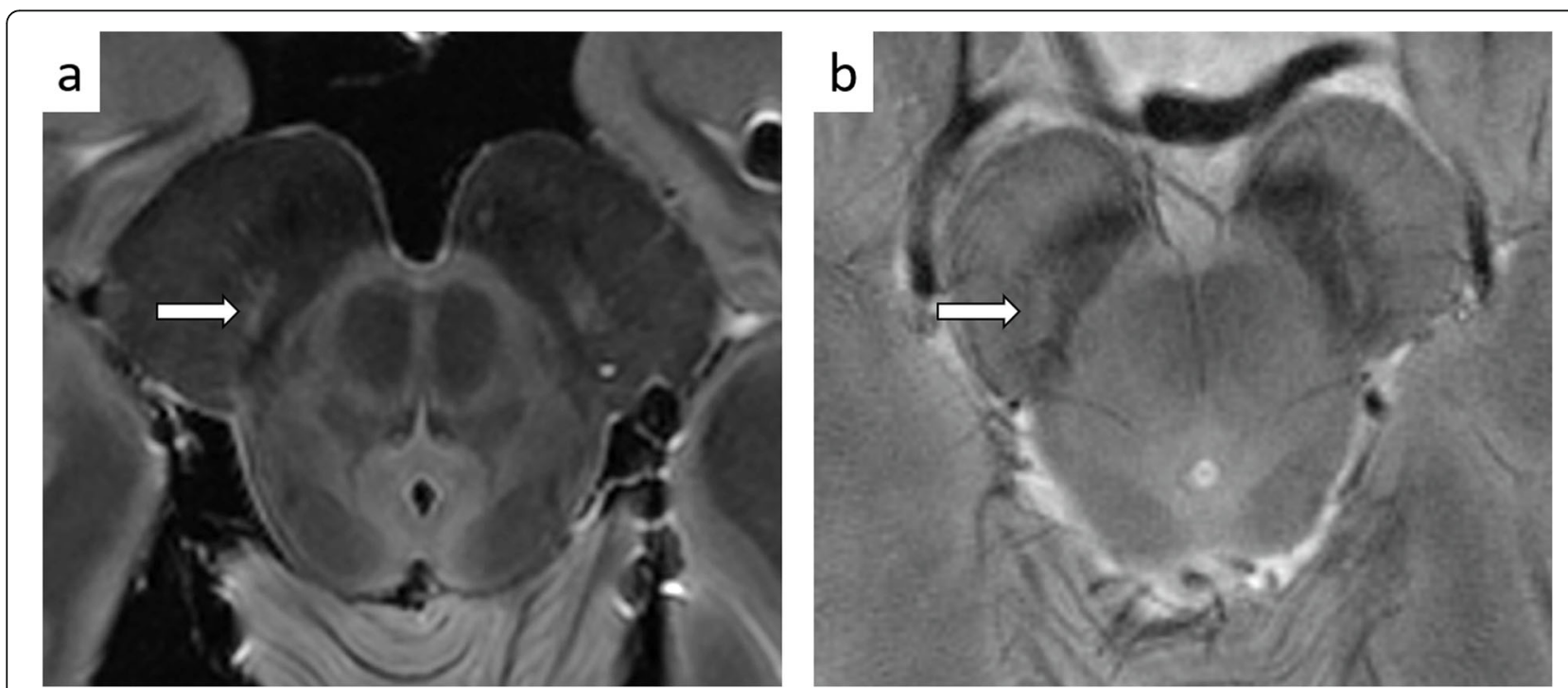

Fig. 2 Ex vivo and in vivo MR imaging of the SN. The oval-shaped hyperintense formation indicated by arrows corresponds to nigrosome 1 (N1). a Proton density axial image of an ex-vivo sample. $\mathbf{b}$ Gradient echo imaging at high resolution allows to define the N1 formation with typical "swallow tail appearance" in healthy subjects in vivo 

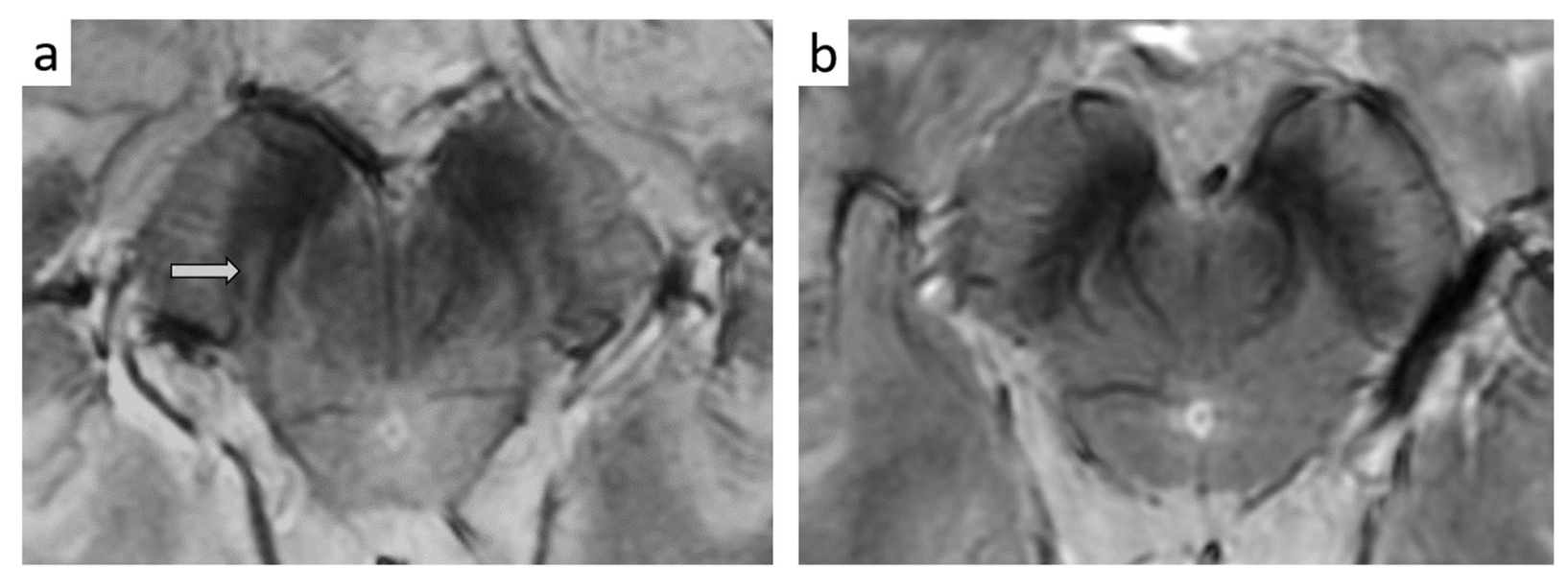

Fig. 3 3D multi-echo T2*-weighted images of the substantia nigra at the level of the nigrosome 1 (arrow) in a an RBD patient with a normal imaging of the substantia nigra who has not developed symptoms or signs of parkinsonism in the follow-up; $\mathbf{b}$ an RBD patient with abnormal findings at imaging (the nigrosome 1 was not visible), who eventually converted to PD

generate quantitative maps of magnetic susceptibility (QSM), which enable the measurement of local susceptibility and reflect the amount of iron content in the SN of PD patients [2]. An increase of QSM values in the SN of PD patients at $7 \mathrm{~T}$ has been reported [109], which has opened the perspective to quantify nigrosome degeneration along the disease course and its changes in response to therapy.

The immunohistochemical evaluation of the SN pars compacta reveals five calbindin-negative nigrosomes (N1 to N5) [98] that can be identified in ex vivo samples by using UHF MR [105]. All nigrosomes 1-5 have recently been detected in vivo in PD patients and controls using high-resolution iron-sensitive 7-T MRI. In PD patients the nigrosome 1 showed the most pronounced decrease in $\mathrm{T} 2 \%$-weighted signal and the best correlation to clinical scales (Unified Parkinson's Disease Rating Scale, UPDRS) even in the earliest stages of disease, confirming its role as a measure of disease severity $[110,111]$.

Considering the long premotor period before the manifestation of motor symptoms, a preclinical diagnosis of PD would be desirable to test possible diseasemodifying therapies. With this aim, a 7-T MR investigation of the midbrain has been attempted also in patients with predisposing conditions to develop PD. Carriers of gene mutation (parkin, PINK1, LRRK-2, DJ-1) [112], or patients with rapid eye movement behavior disorder (RBD) [113, 114] exhibited altered nigral anatomy with absent nigrosome representation in a preclinical condition (Fig. 3). Longitudinal studies on these subjects could provide important insights on the role of iron-sensitive 7-T MRI as a potential prognostic biomarker of neurodegeneration.
One of the main goals of MRI in PD is differential diagnosis. To investigate the causative role of nigrosome degeneration in PD, some studies have been conducted in patients with secondary parkinsonism without conventional MR abnormalities, such as drug-induced parkinsonism, and in patients with suspected vascular pseudoparkinsonism. Drug-induced parkinsonism occurs in the absence of presynaptic dopaminergic deficits: in such case, in accordance with the normal DAT scan, the visualization of nigrosome 1 is preserved [115]. Similarly, the nigrosome preservation characterizes patients with essential tremor, allowing a differential diagnosis with PD with high diagnostic accuracy [116]. These studies were conducted at $3 \mathrm{~T}$ and it can be expected that a comparative investigation with a 7-T system might reveal an increased confidence in the differential diagnosis.

The most frequent and challenging differential diagnosis attempted with 7-T MRI and iron sensitive sequences is between idiopathic PD and atypical parkinsonisms, particularly in the early stages of disease [117] when a significant number of patients have an incorrect clinical diagnosis.

UHF MR imaging studies of atypical parkinsonisms reported that anatomical changes of $\mathrm{SN}$ are not exclusive of PD; however, the impairment of the $\mathrm{SN}$ is not univocal in the different types of neurodegenerative parkinsonisms. The majority of patients with multiple system atrophy-clinical phenotype $\mathrm{p}$ (MSA-p) studied at $7 \mathrm{~T}$ have a loss of the signal hyperintensity corresponding to nigrosome 1, a pathological finding that is not invariably present in patients with MSA-c $[99,118]$. A preservation of dopaminergic nigro-striatal function [119] reported with SPECT corresponds to an unremarkable imaging of the substantia nigra in some cases of corticobasal degeneration [120]. On the other hand, in progressive 
supranuclear palsy (PSP) the SN is invariably altered, with the loss of nigrosome 1 hyperintensity. In this type of atypical parkinsonism, the signal hypointensity at $7 \mathrm{~T}$ is more evident in the medial part of the pars compacta [120] where the iron deposition is prominent [121].

In summary, nigrosome imaging differentiates neurodegenerative from non-neurodegenerative parkinsonisms but, similarly to DATscan, is less effective in distinguishing PD from atypical parkinsonisms [122].

\section{Other potentialities for 7-T MR in PD}

The dopaminergic neurons of the $\mathrm{SN}$ and the noradrenaline-containing neurons of the locus coeruleus (LC) contain high levels of neuromelanin, which is the target of neuromelanin-sensitive MRI. In PD, nondopaminergic pathways such as noradrenaline neurons of the pons are involved in the neurodegenerative process [123].

The LC is the largest nucleus of noradrenergic neurons in the brain: it was indicated as the most affected extra-striatal area in PD [124], and neuromelanin depletion in the LC probably precedes that in the SN [125]. The depiction of the LC with MRI in vivo is based on the presence of neuromelanin, a paramagnetic pigment produced in noradrenergic neurons, and is achieved by using a T1-weighted Turbo Spin Echo sequence [126]. By leveraging on the different tissue relaxation times, which are fieldstrength-dependent, and on the increased SNR, which enables higher spatial resolution, several 7-T MR techniques provide detectable contrast between the LC and surrounding tissue. In particular, T1-weighted imaging with spectral presaturation inversion recovery (SPIR) provides higher contrast than Turbo Spin Echo (TSE)-based sequences at lower field strength. Notably, the small isotropic voxels that can be obtained at $7 \mathrm{~T}$ are an important advantage when visualizing small structures such as the LC [127]. The LC of patients with $\mathrm{PD}$ is currently under investigation also with Magnetization Transfer (MT)-weighted imaging at $7 \mathrm{~T}$ [128].

7-T MR spectroscopy has been used to investigate brainstem nuclei aiming to reveal non-dopaminergic system impairment that cannot be disclosed at conventional magnetic field strength. UHF provides not only improved SNR for MRS techniques, but also increased spectral resolution and reduced chemical shift dispersion of peaks [129]. Single-voxel 7-T MRS enabled the detection of metabolites including GABA [130]: in PD, increased GABAergic activity in the pons has been supposed to cause a reduction of excitatory outflow of the noradrenergic tone of the LC to the neurons of the substantia nigra. MRS at UHF could therefore reveal the earliest changes of metabolite concentrations in the brainstem of PD patients [131]. Indeed, UHF MRS of the brainstem revealed GABA increase in the pons relative to putamen in PD [132], indicating an earlier pathological involvement of the brainstem before nigrostriatal affection, according to the caudo-rostral spreading of synucleinopathy [133].

7-T MRI has also been aimed at to facilitate the surgical therapy of PD. Deep Brain Stimulation (DBS) is a well-established surgical technique for treating PD, consisting of the placement of stimulating electrodes within the motor component of the subthalamic nucleus (STN) to inhibit parkinsonian symptoms. The targeting of the STN can be done with stereotactic atlases or directly with MRI. Recently, the direct targeting of the STN [134] has been demonstrated to be feasible [135]. In addition, 7-T MRI data have been used to parcellate the globus pallidus into motor, associative and limbic regions in individual subjects to improve the precision of electrode placement [136]. Recently, a machine learning method based on $7 \mathrm{~T}$ data enabled the accurate prediction of the STN shape and position on the clinical image for targeting the STN in DBS [137], opening new perspectives in functional neurosurgery.

In conclusion, UHF MR in PD is currently used to identify a surrogate marker of disease with the aim to overcome the intrinsic limitations of conventional magnetic field strength MR, and until now $7 \mathrm{~T}$ has provided a better understanding of the anatomy and pathology of different brain structures involved in the pathologic processes in parkinsonisms.

\section{Amyotrophic lateral sclerosis}

Amyotrophic lateral sclerosis (ALS) is a progressive and clinically heterogeneous neurological disease affecting both upper and lower motor neurons [138, 139]. Up to about $50 \%$ of patients also show cognitive or behavioral disturbances, and frontotemporal dementia is diagnosed in about $25 \%$ of these cases [140]. The etiopathogenesis of the disease is not completely known; both genetic and environmental factors have a pivotal role [141] and neuroinflammation, oxidative stress and glutamate induced excitotoxicity have been investigated as possible pathogenetic mechanisms [142-144].

The typical features of the upper motor neuron pathology are the loss of pyramidal cells of Betz in the layer $\mathrm{V}$ of the primary motor cortex together with the axonal loss and gliosis in the corticospinal tract; the lower motor neuron pathology, instead, is reflected by loss of motor neurons in the motor nuclei of the brainstem and in the anterior horn of the spinal cord $[145,146]$. Moreover, reactive microglia/macrophages were found to be abundant in the affected areas of the brain and the spinal cord [145]. 
Even though MRI is not currently recommended for the specific search of brain abnormalities reported in ALS patients [147], imaging of the central nervous system has gained interest in the past two decades mainly with the purpose of finding, non-invasively, accurate biomarkers of disease which could aid early diagnosis and provide surrogate endpoints in clinical trials $[148,149]$. Indeed, MRI can reveal the consequences of pathological changes, and MRS can detect the associated metabolic abnormalities. The advent of UHF (7-T) MR has further increased the interest in this field. At $7 \mathrm{~T}$, the higher signal-to-noise ratio, sensitivity to magnetic susceptibility effects, spatial resolution of images, and spectral resolution of metabolites have allowed and could further enable in the future a more detailed depiction of morphological, metabolic and functional abnormalities in the brain and spinal cord of ALS patients, improving the accuracy in detecting motor neuron pathology with both qualitative and quantitative techniques.
Brain

\section{T2*-weighted imaging and quantitative susceptibility} mapping

7-T MRI has enabled the detailed depiction of the radiological anatomy of the primary motor cortex in normal conditions and its changes in ALS patients. Even though MRI cannot directly reveal pathology at the cellular level, it can show the consequences of Betz cells loss and intracortical accumulation of microglia. As neuronal loss can be revealed by the cortical thinning, the presence of ferritin-laden microglial cells can be unveiled indirectly by the abnormal hypointense rim in the motor cortex in T2*-weighted imaging. The high ferritin content in microglial cells, whose meaning in the disease process has not been fully clarified yet, causes the shortening of the relaxation time $\mathrm{T} 2$ and the consequent $\mathrm{T} 2 *$ hypointensity [69].

The primary motor cortex was shown to have a typical MR appearance characterized by a thin superficial

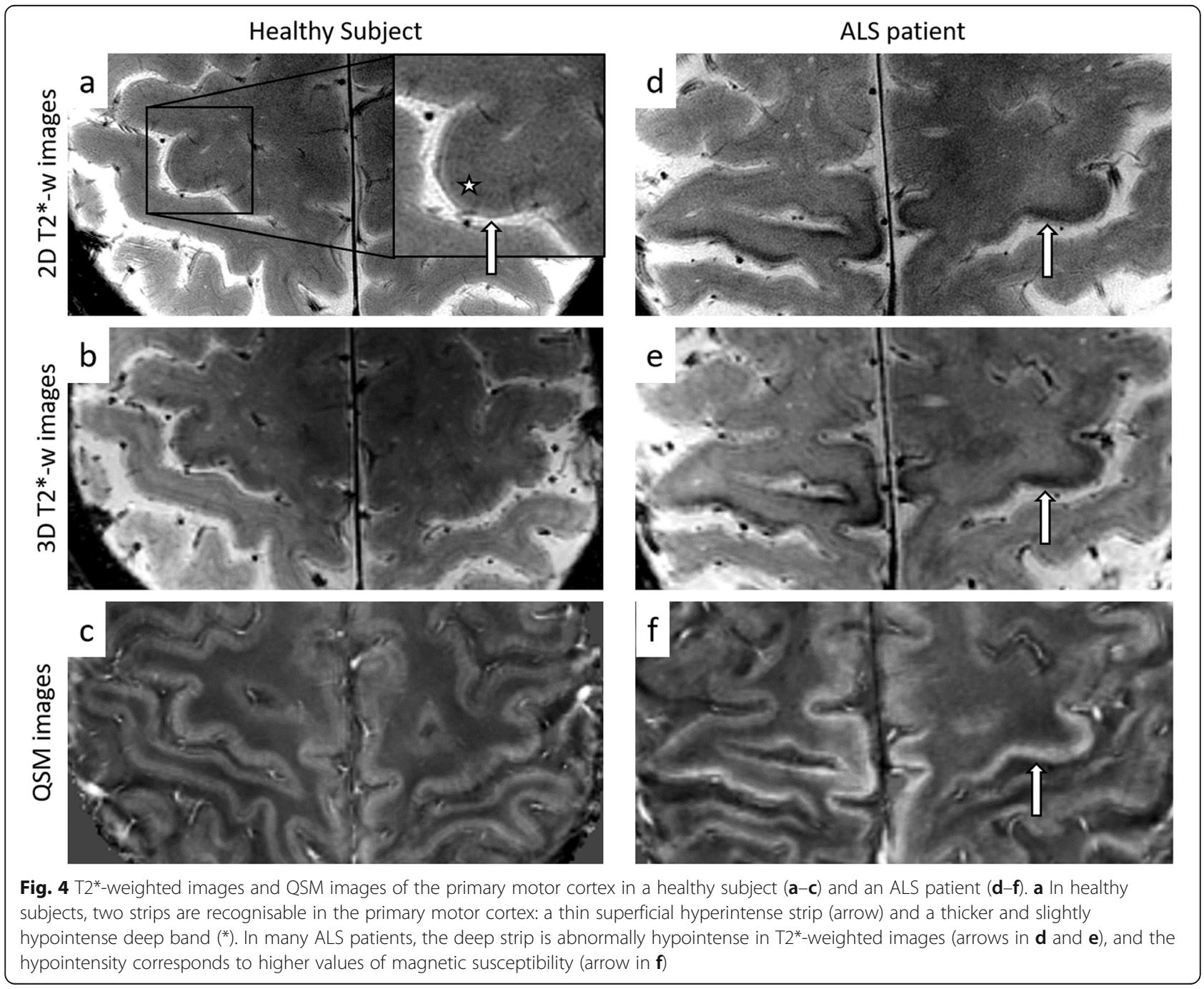


hyperintense strip, always preserved in ALS patients, which lies just above a thicker and slightly hypointense band, radiologically affected in ALS [150] (Fig. 4). In many patients, in fact, the deep strip was shown to be thinner and more hypointense than normal [150] (Fig. $4 \mathrm{~d}$, e), with fewer pyramidal cells of Betz and many ferritin-laden microglial cells [69].

The cortical signal hypointensity, described for the first time in T2-weighted images of ALS patients in 1993 [151, $152]$ and reported with variable sensitivity [153, 154], was proved to be more visible and accurate in identifying patients at $7 \mathrm{~T}$ than at $3 \mathrm{~T}[155,156]$. It has been proposed as a sign of upper motor neuron impairment [152] and that hypothesis has been confirmed in recent studies. The regional grade of cortical atrophy and hypointensity was found to correspond to a somatotopic functional disability related to the upper motor neuron pathology [150] and can differ from one body region to another $[150,155]$ : the lower the $\mathrm{T}_{2}^{*}$ signal intensity and the thickness of the deep layers of the primary motor cortex, the worse the upper motor neuron impairment of the corresponding body regions [150].

The signal hypointensity has been further investigated and the iron concentration estimated using QSM. Differently from conventional $\mathrm{T} 2$ *-weighted sequences, quantitative susceptibility maps provide objective and more reproducible data for cortical assessment. Even though the mean magnetic susceptibility of a tissue is influenced by all the components, iron is the prevalent source of magnetic susceptibility-based contrast in the cerebral cortex [157] and its expected concentration has been proven to correlate with magnetic susceptibility measures [158]. The marked hypointensity in the primary motor cortex of ALS patients was confirmed to be related to paramagnetic tissue [158] (Fig. 4f); moreover, the cortical magnetic susceptibility, which is associated with the degree of microglial activation [159], was found to significantly correlate with the clinical upper motor neuron impairment [158].

Therefore, although cortical atrophy, hypointensity, and increased magnetic susceptibility were known findings in many ALS patients also at conventional magnetic fields [151-153, 155, 160-163], their characterization and accuracy in diagnosing the upper motor neuron pathology have been improved by using $7-\mathrm{T}$ MR systems.

\section{Magnetic resonance spectroscopy}

MRS can reveal metabolic changes of the brain related to one or more key points of ALS pathology. This is true at conventional magnetic fields and even more so at $7 \mathrm{~T}$, where the higher signal-to-noise ratio and spectral resolution can lead to an increased precision in metabolite quantification and detectability of low concentration metabolites [164].

Both ${ }^{1} \mathrm{H}$ and ${ }^{31} \mathrm{P}$ MRS have been employed at $7 \mathrm{~T}$ : the former has enabled the assessment of changes in the tissue concentration of mainly $\mathrm{N}$-acetylaspartate (NAA, a marker of neuronal density and integrity [165]), myoinositol (mI, a marker of glial cells [166]), glutamate (Glu, the main excitatory neurotransmitter), and gamma-aminobutyric acid (GABA, the main inhibitory neurotransmitter in the cortex); ${ }^{31} \mathrm{P} 7-\mathrm{T}$ MRS has been employed to investigate the energetic status of the cells and the membrane metabolism.

MRS in ALS patients There is only a small number of published studies investigating metabolic changes in ALS patients at $7 \mathrm{~T}$ and they focused mainly on the primary motor cortex $[167,168]$. Both NAA and total NAA (tNAA) were found to be significantly decreased in the precentral gyrus of ALS patients compared to controls [167], and the level of tNAA was shown to depend on the diagnostic subcategory, with probable/definite ALS being more affected than possible ALS [168]. Compared to controls, mI was higher in the primary motor cortex of patients, in particular in probable/definite ALS patients [168].

Reported results about Glu are conflicting, with significantly reduced levels in the precentral gyrus of patients in one study [167] but not in the other [168]. Interestingly, the significant and positive correlation between Glu and NAA levels suggests that the Glu reduction in ALS patients is driven by neuronal loss [167]. On the contrary, GABA was not found to be significantly different between patients and controls [167].

The effect of taking riluzole, a glutamatergic neurotransmission inhibitor [169], was also investigated. Addressing the suggested glutamate induced excitotoxicity pathogenetic mechanisms of ALS, riluzole might influence levels of Glu but also those of metabolites related to neuronal density and neuroinflammation. Even though no difference was observed between riluzoletreated and riluzole-naive patients, riluzole-naive patients showed lower tNAA/mI than controls [168].

Another topic in MRS is the search for a relationship between clinical data and metabolite concentrations or ratios. At $7 \mathrm{~T}$, the greater disease severity (assessed with the Revised Amyotrophic Lateral Sclerosis Functional Rating Scale, ALSFRS-R) was found to be associated with lower levels of tNAA, tNAA/tCr, tNAA/mI, and Glu in the precentral gyrus [168], and the heavier clinical upper motor neuron impairment with higher $\mathrm{mI} /$ tNAA in the motor cortex only in one study [167]. Unfortunately, different research groups employ different clinical scales to assess upper motor neuron dysfunction, and they could have different sensitivity to pathology. 
When interpreting results of MRS studies, some factors have to be considered. In single voxel studies, a limited part of the potentially affected tissue is investigated, and disease duration at the time of the MR acquisition and clinical phenotype can influence the results. Synaptic concentrations of Glu and GABA might be influenced by riluzole $[169,170]$, the precision of GABA quantification might not to be sufficient even at $7 \mathrm{~T}$ [168], and Glu is located in both the intracellular and extracellular space, even though the extracellular concentration is much higher than the intracellular one [171]. Therefore, changes in Glu concentration revealed by MRS could be driven by the reduced intracellular concentration via neuronal loss, increased extracellular concentration responsible for excitotoxicity or both, with the possible influence of riluzole.

MRS in asymptomatic C9orf72 repeat expansion carriers C9orf72 hexanucleotide repeat expansion is the most frequent gene mutation in both familial and sporadic ALS cases $[172,173]$ and is associated with an almost full penetrance by 80 years [172]. Therefore, investigating asymptomatic C9orf72 repeat expansion carriers might provide non-invasively new insights into the pathophysiology of ALS and possible presymptomatic alterations, and some metabolic changes have been documented in many brain regions using both $1 \mathrm{H}$ MRS and 31P MRS.

Compared to non-carriers, in C9orf72 repeat expansion carriers lower levels of $\mathrm{tNAA} / \mathrm{tCr}$ and $\mathrm{Glu} / \mathrm{tCr}$ were found in the left putamen and lower levels of Glu/tNAA were observed in the putamen and thalamus of the left hemisphere [174]. These results might reflect a lower concentration of neurons and Glu per neuron, whose meaning needs further research to be elucidated. Moreover, glycerophosphoethalonamine-to-phosphocreatine ratio (GPE/PCr) and uridine diphosphoglucose-tophosphocreatine ratio (UDPG/PCr) were found to be significantly higher in many brain regions of asymptomatic carriers [175]. Being GPE one of the cell membrane degradation products and UDPG a precursor of glycogen, these results might reflect an increased catabolism of the cell membranes and an imbalance of energy metabolism, respectively [175].

In conclusion, MRS studies at ultra-high-field confirmed lower levels of NAA and higher levels of $\mathrm{mI}$ in the precentral gyrus of ALS patients, provided new insight into the pre-symptomatic brain changes, but showed inconsistent results about Glu. Further studies including larger cohorts of patients and subjects at high risk of developing the disease are needed, using whole-brain and multi-nuclear MRS, to explore metabolic brain changes and possible patterns related to diagnostic subcategories, clinical phenotypes or pharmacological treatments.
Quantitative T1 mapping, magnetization transfer contrast, and amide proton transfer-weighted imaging

The corticospinal tract has been widely investigated in ALS using DTI at conventional magnetic fields, and reduced fractional anisotropy was consistently reported [176]. The basis for this diffusivity change, explored at 7 $\mathrm{T}$ by combining quantitative T1 mapping, magnetization transfer ratio and amide proton transfer-weighted imaging, might be more likely related to gliosis and expansion of the extracellular matrix rather than to demyelination [177].

\section{Spinal cord}

While UHF MR has the potential to greatly improve spinal cord imaging, several technical issues, such as physiological noise and inhomogeneities of the static magnetic and radiofrequency fields, have limited its application in clinical studies. A number of possible solutions have been and are being explored to overcome these limitations [178]. Recent studies have shown the feasibility of conventional imaging [179], MRS [180], glutamate-weighted chemical exchange saturation transfer (CEST) MR imaging [181] and diffusion tensor imaging of the spinal cord [182], opening the door to their possible future applications in clinical research. So far, only two studies investigating the spinal cord in ALS patients at $7 \mathrm{~T}$ have been published; one study assessed in vivo alterations [183] and the other made a comparison between MRI and histology in an ex vivo specimen [159].

\section{Conventional imaging}

Imaging the spinal cord at very high resolution (about $200-400 \mu \mathrm{m}$ in-plane) can enable the depiction of alterations occurring in ALS patients. It has the potentiality of representing in the same images signal changes of the lateral columns and the atrophy of the anterior horn of the spinal cord, which reflect upper and lower motor neuron degeneration, respectively.

Signal hyperintensity in the lateral segments of the cervical spinal cord has been documented at $7 \mathrm{~T}$ in one ALS patient [183] and in an ex vivo specimen [159] but not in a control subject [183]. The location of such signal alteration in patients together with the presence of histological signs of degeneration [159] have suggested the hyperintensity as a sign of corticospinal tract degeneration [183].

On the other hand, the detailed differentiation between white and grey matter and the measurement of the grey matter area have been proven to be feasible at $7 \mathrm{~T}$ [179] but not employed yet in clinical studies. 


\section{Diffusion tensor imaging}

So far, there are no published accounts in the literature about DTI of the spinal cord at $7 \mathrm{~T}$ in ALS patients in vivo. However, in an ex vivo specimen, the signal hyperintensity and histological fibre degeneration in the lateral segments of the cervical spinal cord were found to parallel the significant decrease of fractional anisotropy and increase of mean diffusivity [159]. DTI metrics can therefore contribute to further assess the upper motor neuron pathology in the spinal cord of ALS patients.

In conclusion, magnetic resonance techniques at 7 $\mathrm{T}$ have provided new insights into the pathophysiology of ALS. They have allowed revealing morphological, quantitative and metabolic changes in the central nervous system, mainly in the primary motor area and in the corticospinal tract, which are related to pathologic abnormalities that occur in the disease. Technical developments and overcoming current issues and limitations will open interesting prospects for future research.

\section{Conclusion}

This review has described how UHF MR has recently impacted on clinical studies addressing AD, PD, and ALS and provides new avenues for research. Researchers have capitalized on higher SNR, signal sensitivity, and improved spatial resolution offered by UHF-MRI, to obtain a clearer depiction of the anatomical regions involved in each disease. The pathological changes of brain function and circuitry have been studied with fMRI with improved BOLD contrast and spatial detail, while the increased spectral resolution and reduced chemical shift dispersion enabled by UHF MRS have shed new light on the metabolic changes occurring in each pathology.

The introduction of UHF scanners allowed to identify radiological signs in neurodegenerative disorders, previously undetectable at magnetic fields $\leq 3 \mathrm{~T}$ : the detection of structural and functional degeneration within the hippocampus of AD patients, loss of anatomical integrity of the substantia nigra in PD and increased magnetic susceptibility in the primary motor cortex of ALS patients with upper motor neuron degeneration are examples of the clinical/radiological impact deriving from the current research in neurodegenerative disorders with UHF.

UHF scanners have also offered new ground for more advanced and challenging techniques, such as CEST imaging and magnetic resonance of nuclei other than ${ }^{1} \mathrm{H}$ (x-nuclei). However, at the present time, the use of such techniques is still little documented in the published literature on neurodegenerative diseases.
While on the one hand, there is no doubt about the clear advantages offered by UHF MR, and on the other hand, some limitations still restrict its applicability mostly to the field of clinical research. However, the steady technological progress in MR hardware and acquisition techniques, including for example the development of improved parallel imaging transmission systems, gradient coils, and prospective motion correction methods, together with the recent introduction in the market of $7 \mathrm{~T}$ scanners certified for diagnostic use, suggest that in the near future UHF MR might have a further increasing impact in the study and diagnosis of $\mathrm{AD}$, $\mathrm{PD}$, and ALS.

\section{Abbreviations \\ AD: Alzheimer's disease; ALS: Amyotrophic lateral sclerosis; CSF: Cerebro spinal fluid; DBS: Deep brain stimulation; DTI: Diffusion tensor imaging; LC: Locus coeruleus; MR: Magnetic resonance; MRI: Magnetic resonance imaging; MRS: Magnetic resonance spectroscopy; MSA: Multiple system atrophy; PD: Parkinson's disease; QSM: Quantitative susceptibility mapping; RBD: Rapid-eye-movement behavioral disorder; SN: Substantia nigra; SNR: Signal-to-noise ratio; STN: Sub thalamic nucleus; SWI: Susceptibility- weighted imaging; TOF: Time of flight; UHF: Ultra-high field}

\section{Authors' contributions}

M. Cosottini made substantial contributions to the conception of this article and composed the PD section; E. Düzel and O. Speck composed the AD section; G. Donatelli composed the ALS section; M. Costagli composed the introductory and conclusive sections and substantively revised the article. All authors read and approved the final manuscript.

\section{Funding}

This study was partially supported by grant RF-2013-02354829, funded by the Italian Ministry of Health and co-funded by Regione Toscana. E Duzel was supported by the German Research Foundation (DFG, SFB 779 A07, SFB 1315 TP B06) and the Human Brain Project (SGA3, WP1, WP2). Open Access funding enabled and organized by Projekt DEAL.

Availability of data and materials

Not applicable (literature review).

\section{Declarations}

Ethics approval and consent to participate

Not applicable (Literature review).

Consent for publication

Not applicable.

\section{Competing interests}

All authors declare that they have no competing interests.

\section{Author details}

${ }^{1}$ Otto-von-Guericke University Magdeburg, Magdeburg, Germany. ${ }^{2}$ German Center for Neurodegenerative Diseases (DZNE), Magdeburg, Germany. ${ }^{3}$ University College London, London, UK. ${ }^{4}$ IRCCS Stella Maris, Pisa, Italy. ${ }^{5}$ University of Genoa, Genova, Italy. ${ }^{6}$ Fondazione Imago 7, Pisa, Italy. ${ }^{7}$ Azienda Ospedaliero Universitaria Pisana, Pisa, Italy. ${ }^{8}$ University of Pisa, Pisa, Italy.

Received: 15 October 2020 Accepted: 7 April 2021

Published online: 26 August 2021

References

1. Moser E, Stahlberg F, Ladd ME, Trattnig S (2012) 7-T MR-from research to clinical applications? NMR Biomed 25:695-716 https://doi.org/10.1002/ nbm.1794 
2. Liu C, Li W, Tong KA, Yeom KW, Kuzminski S (2015) Susceptibility-weighted imaging and quantitative susceptibility mapping in the brain. J Magn Reson Imaging 42:23-41 https://doi.org/10.1002/jmri.24768

3. Yacoub E, Harel N, Uğurbil K (2008) High-field fMRI unveils orientation columns in humans. Proc Natl Acad Sci U S A 105:10607-10612 https://doi. org/10.1073/pnas.0804110105

4. Fracasso A, Luijten PR, Dumoulin SO, Petridou N (2017) Laminar imaging of positive and negative BOLD in human visual cortex at 7 T. Neuroimage 164: 100-111 https://doi.org/10.1016/j.neuroimage.2017.02.038

5. Ojemann JG, Akbudak E, Snyder AZ, McKinstry RC, Raichle ME, Conturo TE (1997) Anatomic localization and quantitative analysis of gradient refocused echo-planar fMRI susceptibility artifacts. Neuroimage 6:156-167 https://doi. org/10.1006/nimg.1997.0289

6. Triantafyllou C, Hoge RD, Krueger G et al (2005) Comparison of physiological noise at 1.5 T, $3 \mathrm{~T}$ and $7 \mathrm{~T}$ and optimization of fMRI acquisition parameters. Neuroimage 26:243-250 https://doi.org/10.1016/j. neuroimage.2005.01.007

7. Zaitsev M, Maclaren J, Herbst M (2015) Motion artifacts in MRl: a complex problem with many partial solutions. J Magn Reson Imaging 42:887-901 https://doi.org/10.1002/jmri.24850

8. Jezzard P, Clare S (1999) Sources of distortion in functional MRI data. Hum Brain Mapp 8:80-85. https://doi.org/10.1002/(SICl)1097-0193(1999)8:2/3< 80::AID-HBM2>3.0.CO;2-C

9. Gras V, Boland M, Vignaud A et al (2017) Homogeneous non-selective and slice-selective parallel-transmit excitations at 7 Tesla with universal pulses: a validation study on two commercial RF coils. PLoS One 12:e0183562 https:/ doi.org/10.1371/journal.pone.0183562

10. Ladd ME, Bachert P, Meyerspeer M et al (2018) Pros and cons of ultra-highfield MRI/MRS for human application. Prog Nucl Magn Reson Spectrosc 109: 1-50 https://doi.org/10.1016/.jpnmrs.2018.06.001

11. Jack CR, Bennett DA, Blennow $K$ et al (2018) NIA-AA research framework: toward a biological definition of Alzheimer's disease. Alzheimers Dement 14:535-562 https://doi.org/10.1016/j.jalz.2018.02.018

12. Young PNE, Estarellas M, Coomans E et al (2020) Imaging biomarkers in neurodegeneration: current and future practices. Alzheimers Res Ther 12:49 https://doi.org/10.1186/s13195-020-00612-7

13. Committee for Medicinal Products for Human Use (CHMP) (2011) Qualification opinion of low hippocampal volume (atrophy) by MRI for use in clinical trials for regulatory purpose-in pre-dementia stage of Alzheimer's disease

14. Hill DLG, Schwarz AJ, Isaac M et al (2014) Coalition Against Major Diseases/ European Medicines Agency biomarker qualification of hippocampal volume for enrichment of clinical trials in predementia stages of Alzheimer's disease. Alzheimers Dement 10:421-429.e3 https://doi.org/10.1016/j.jalz.2 013.07.003

15. Rohrer JD, Nicholas JM, Cash DM et al (2015) Presymptomatic cognitive and neuroanatomical changes in genetic frontotemporal dementia in the Genetic Frontotemporal dementia Initiative (GENFI) study: a cross-sectional analysis. Lancet Neurol 14:253-262 https:/doi.org/10.1016/S1474-4422(14)70324-2

16. Jack CR, Barnes J, Bernstein MA et al (2015) Magnetic resonance imaging in Alzheimer's disease neuroimaging initiative 2. Alzheimers Dement 11:740756 https://doi.org/10.1016/j.jalz.2015.05.002

17. Wisse LEM, Chételat G, Daugherty AM et al (2020) Hippocampal subfield volumetry from structural isotropic $1 \mathrm{~mm} 3 \mathrm{MRI}$ scans: a note of caution. Hum Brain Mapp 42:539-550 https://doi.org/10.1002/hbm.25234

18. Düzel E, Acosta-Cabronero J, Berron D et al (2019) European Ultrahigh-Field Imaging Network for Neurodegenerative Diseases (EUFIND). Alzheimers Dement Diagn Assess Dis Monit 11:538-549 https://doi.org/10.1016/j.da dm.2019.04.010

19. Berron D, Vieweg P, Hochkeppler A et al (2017) A protocol for manual segmentation of medial temporal lobe subregions in 7 Tesla MRI. Neuroimage Clin 15:466-482 https://doi.org/10.1016/.nicl.2017.05.022

20. Maass A, Berron D, Libby LA, Ranganath C, Düzel E (2015) Functional subregions of the human entorhinal cortex. Elife 4:1-20 https://doi.org/10. 7554/eLife.06426

21. Maass A, Berron D, Harrison TM et al (2019) Alzheimer's pathology targets distinct memory networks in the ageing brain. Brain 142:2492-2509 https:// doi.org/10.1093/brain/awz154

22. Braak H, Del Tredici K (2015) The preclinical phase of the pathological process underlying sporadic Alzheimer's disease. Brain 138:2814-2833 https://doi.org/10.1093/brain/awv236
23. Berron D, van Westen D, Ossenkoppele R, Strandberg O, Hansson O (2020) Medial temporal lobe connectivity and its associations with cognition in early Alzheimer's disease. Brain 143:1233-1248 https:/doi.org/10.1093/brain/awaa068

24. de Flores R, Berron D, Ding SL et al (2020) Characterization of hippocampal subfields using ex vivo MRI and histology data: lessons for in vivo segmentation. Hippocampus 30:545-564 https://doi.org/10.1002/hipo.23172

25. Maclaren J, Herbst M, Speck O, Zaitsev M (2013) Prospective motion correction in brain imaging: a review. Magn Reson Med 69:621-636 https:// doi.org/10.1002/mrm.24314

26. Newton A, McGugin R, Gauthier I (2019) Behavioral correlates to laminar thickness within the cortex. In: International society for magnetic resonance in medicine, $\mathrm{p} 0338$

27. Kulason S, Tward DJ, Brown T et al (2019) Cortical thickness atrophy in the transentorhinal cortex in mild cognitive impairment. Neuroimage Clin 21: 101617 https://doi.org/10.1016/.nicl.2018.101617

28. Kuehn E, Sereno MI (2018) Modelling the human cortex in three dimensions. Trends Cogn Sci 22:1073-1075 https://doi.org/10.1016/j.tics.201 8.08.010

29. Betts MJ, Kirilina E, Otaduy MCG et al (2019) Locus coeruleus imaging as a biomarker for noradrenergic dysfunction in neurodegenerative diseases. Brain 142:2558-2571 https://doi.org/10.1093/brain/awz193

30. Betts MJ, Cardenas-Blanco A, Kanowski M et al (2019) Locus coeruleus MRI contrast is reduced in Alzheimer's disease dementia and correlates with CSF Aß levels. Alzheimers Dement Diagn Assess Dis Monit 11:281-285 https:// doi.org/10.1016/j.dadm.2019.02.001

31. Priovoulos N, Jacobs HIL, Ivanov D, Uludağ K, Verhey FRJ, Poser BA (2018) High-resolution in vivo imaging of human locus coeruleus by magnetization transfer MRI at 3 T and 7 T. Neuroimage 168:427-436 https:/ doi.org/10.1016/j.neuroimage.2017.07.045

32. Dichgans M (2019) Dementia risk after transient ischaemic attack and stroke. Lancet Neurol 18:223-225 https://doi.org/10.1016/S1474-4422(18)30497-6

33. Salman RA-S, McGoohan K, Rodrigues M, Dichgans M (2016) Dementia after stroke due to intracerebral haemorrhage. Lancet Neurol 15:779-780 https:// doi.org/10.1016/S1474-4422(16)30092-8

34. Conijn MMA, Geerlings MI, Biessels GJ et al (2011) Cerebral microbleeds on MR imaging: comparison between 1.5 and 7 T. AJNR Am J Neuroradiol 32: 1043-1049 https://doi.org/10.3174/ajnr.A2450

35. Kuijf HJ, de Bresser J, Geerlings Ml et al (2012) Efficient detection of cerebral microbleeds on $7.0 \mathrm{t} \mathrm{mr}$ images using the radial symmetry transform. Neuroimage 59:2266-2273 https://doi.org/10.1016/..neuroimage.2011.09.061

36. Jouvent E, Poupon C, Gray F et al (2011) Intracortical infarcts in small vessel disease: a combined 7-T postmortem MRI and neuropathological case study in cerebral autosomal-dominant arteriopathy with subcortical infarcts and leukoencephalopathy. Stroke 42:e27-e30 https://doi.org/10.1161/STROKEA HA. 110.594218

37. van Veluw SJ, Shih AY, Smith EE et al (2017) Detection, risk factors, and functional consequences of cerebral microinfarcts. Lancet Neurol 16:730740 https://doi.org/10.1016/S1474-4422(17)30196-5

38. Bouvy WH, Kuijf HJ, Zwanenburg JJM et al (2017) Abnormalities of cerebral deep medullary veins on 7 Tesla MRI in amnestic mild cognitive impairment and early Alzheimer's disease: a pilot study. J Alzheimers Dis 57:705-710 https://doi.org/10.3233/JAD-160952

39. Geurts L, Biessels GJ, Luiiten P, Zwanenburg J (2018) Better and faster velocity pulsatility assessment in cerebral white matter perforating arteries with $7 \mathrm{~T}$ quantitative flow MRI through improved slice profile, acquisition scheme, and postprocessing. Magn Reson Med 79:1473-1482 https://doi. org/10.1002/mrm.26821

40. Lindenholz A, van der Kolk AG, Zwanenburg JJM, Hendrikse J (2018) The use and pitfalls of intracranial vessel wall imaging: how we do it. Radiology 286:12-28 https://doi.org/10.1148/radiol.2017162096

41. Zwanenburg JJM, van Osch MJP (2017) Targeting cerebral small vessel disease with MRI. Stroke 48:3175-3182 https://doi.org/10.1161/STROKEA HA.117.016996

42. Bouvy WH, Geurts LJ, Kuijf HJ et al (2016) Assessment of blood flow velocity and pulsatility in cerebral perforating arteries with 7-T quantitative flow MRI. NMR Biomed 29:1295-1304 https://doi.org/10.1002/nbm.3306

43. Perosa V, Priester A, Ziegler G et al (2020) Hippocampal vascular reserve associated with cognitive performance and hippocampal volume. Brain 143 622-634 https://doi.org/10.1093/brain/awz383

44. Spallazzi M, Dobisch L, Becke A et al (2019) Hippocampal vascularization patterns: a high-resolution 7 Tesla time-of-flight magnetic resonance 
angiography study. Neuroimage Clin 21:101609 https://doi.org/10.1016/j. nicl.2018.11.019

45. Jochems ACC, Blair GW, Stringer MS et al (2020) Relationship between venules and perivascular spaces in sporadic small vessel diseases. Stroke 51: 1503-1506 https://doi.org/10.1161/STROKEAHA.120.029163

46. Francis F, Ballerini L, Wardlaw JM (2019) Perivascular spaces and their associations with risk factors, clinical disorders and neuroimaging features: a systematic review and meta-analysis. Int J Stroke 14:359-371 https://doi. org/10.1177/1747493019830321

47. Valdés Hernández MD, Ballerini L, Glatz A et al (2020) Perivascular spaces in the centrum semiovale at the beginning of the 8th decade of life: effect on cognition and associations with mineral deposition. Brain Imaging Behav 14:1865-1875 https://doi.org/10.1007/s11682-019-00128-1

48. Wardlaw JM, Benveniste $H$, Nedergaard $M$ et al (2020) Perivascular spaces in the brain: anatomy, physiology and pathology. Nat Rev Neurol 16:137-153 https://doi.org/10.1038/s41582-020-0312-z

49. Mattern H, Sciarra A, Godenschweger F et al (2018) Prospective motion correction enables highest resolution time-of-flight angiography at $7 \mathrm{~T}$. Magn Reson Med 80:248-258 https://doi.org/10.1002/mrm.27033

50. Mattern H, Sciarra A, Lüsebrink F, Acosta-Cabronero J, Speck O (2019) Prospective motion correction improves high-resolution quantitative susceptibility mapping at 7 T. Magn Reson Med 81:1605-1619 https://doi. org/10.1002/mrm.27509

51. Terry RD, Masliah E, Salmon DP et al (1991) Physical basis of cognitive alterations in alzheimer's disease: synapse loss is the major correlate of cognitive impairment. Ann Neurol 30:572-580 https://doi.org/10.1002/a na.410300410

52. Zhou L, Mclnnes J, Wierda K et al (2017) Tau association with synaptic vesicles causes presynaptic dysfunction. Nat Commun 8:15295 https://doi. org/10.1038/ncomms15295

53. Hoover BR, Reed MN, Su J et al (2010) Tau mislocalization to dendritic spines mediates synaptic dysfunction independently of neurodegeneration. Neuron 68:1067-1081 https://doi.org/10.1016/j.neuron.2010.11.030

54. Menkes-Caspi N, Yamin HG, Kellner V, Spires-Jones TL, Cohen D, Stern EA (2015) Pathological tau disrupts ongoing network activity. Neuron 85:959966 https://doi.org/10.1016/j.neuron.2015.01.025

55. Düzel E, Berron D, Schütze H et al (2018) CSF total tau levels are associated with hippocampal novelty irrespective of hippocampal volume. Alzheimers Dement Diagn Assess Dis Monit 10:782-790 https://doi.org/10.1016/j.da dm.2018.10.003

56. Selkoe DJ (2008) Soluble oligomers of the amyloid $\beta$-protein impair synaptic plasticity and behavior. Behav Brain Res 192:106-113 https://doi.org/10.101 6/j.bbr.2008.02.016

57. Mucke L, Selkoe DJ (2012) Neurotoxicity of amyloid $\beta$-protein: synaptic and network dysfunction. Cold Spring Harb Perspect Med 2:a006338 https://doi. org/10.1101/cshperspect.a006338

58. Palmqvist $\mathrm{S}$, Schöll M, Strandberg $O$ et al (2017) Earliest accumulation of $\beta$ amyloid occurs within the default-mode network and concurrently affects brain connectivity. Nat Commun 8:1214 https://doi.org/10.1038/s41467-01701150-x

59. Pohmann R, Speck O, Scheffler K (2016) Signal-to-noise ratio and MR tissue parameters in human brain imaging at 3, 7, and 9.4 tesla using current receive coil arrays. Magn Reson Med 75:801-809 https://doi.org/10.1002/ mrm. 25677

60. Uludağ K, Müller-Bierl B, Uğurbil K (2009) An integrative model for neuronal activity-induced signal changes for gradient and spin echo functional imaging. Neuroimage 48:150-165 https://doi.org/10.1016/j.neuroimage.2009. 05.051

61. Šišková Z, Justus D, Kaneko $\mathrm{H}$ et al (2014) Dendritic structural degeneration is functionally linked to cellular hyperexcitability in a mouse model of alzheimer's disease. Neuron 84:1023-1033 https://doi.org/10.1016/j.neuron.2 014.10 .024

62. Palop JJ, Mucke L (2016) Network abnormalities and interneuron dysfunction in Alzheimer disease. Nat Rev Neurosci 17:777-792 https://doi. org/10.1038/nrn.2016.141

63. Maass A, Lockhart SN, Harrison TM et al (2018) Entorhinal tau pathology, episodic memory decline, and neurodegeneration in aging. J Neurosci 38: 530-543 https://doi.org/10.1523/JNEUROSCl.2028-17.2017

64. Smith MA, Harris PLR, Sayre LM, Perry G (1997) Iron accumulation in Alzheimer disease is a source of redox-generated free radicals. Proc Natl Acad Sci U S A 94:9866-9868 https://doi.org/10.1073/pnas.94.18.9866
65. Sian-Hülsmann J, Mandel S, Youdim MBH, Riederer P (2011) The relevance of iron in the pathogenesis of Parkinson's disease. J Neurochem 118:939957 https://doi.org/10.1111/j.1471-4159.2010.07132.x

66. Lovejoy DB, Guillemin GJ (2014) The potential for transition metal-mediated neurodegeneration in amyotrophic lateral sclerosis. Front Aging Neurosci 6: 6 https://doi.org/10.3389/fnagi.2014.00173

67. Brettschneider J, Del Tredici K, Toledo JB et al (2013) Stages of pTDP-43 pathology in amyotrophic lateral sclerosis. Ann Neurol 74:20-38 https://doi. org/10.1002/ana.23937

68. McGeer PL, Itagaki S, Akiyama H, McGeer EG (1988) Rate of cell death in parkinsonism indicates active neuropathological process. Ann Neurol 24: 574-576 https://doi.org/10.1002/ana.410240415

69. Kwan JY, Jeong SY, Van Gelderen P et al (2012) Iron accumulation in deep cortical layers accounts for MRI signal abnormalities in ALS: correlating 7 tesla MRI and pathology. PLoS One 7:e35241 https://doi.org/10.1371/journal. pone.0035241

70. Connor JR, Snyder BS, Beard JL, Fine RE, Mufson EJ (1992) Regional distribution of iron and iron-regulatory proteins in the brain in aging and Alzheimer's disease. J Neurosci Res 31:327-335 https://doi.org/10.1002/jnr.4 90310214

71. Wang Y, Liu T (2015) Quantitative susceptibility mapping (QSM): decoding MRI data for a tissue magnetic biomarker. Magn Reson Med 73:82-101 https://doi.org/10.1002/mrm.25358

72. Daugherty AM, Haacke EM, Raz N (2015) Striatal iron content predicts its shrinkage and changes in verbal working memory after two years in healthy adults. J Neurosci 35:6731-6743 https://doi.org/10.1523/ JNEUROSCI.4717-14.2015

73. Callaghan MF, Freund P, Draganski B et al (2014) Widespread age-related differences in the human brain microstructure revealed by quantitative magnetic resonance imaging. Neurobiol Aging 35:1862-1872 https://doi. org/10.1016/j.neurobiolaging.2014.02.008

74. Li W, Wu B, Batrachenko A et al (2014) Differential developmental trajectories of magnetic susceptibility in human brain gray and white matter over the lifespan. Hum Brain Mapp 35:2698-2713 https://doi.org/10.1 002/hbm.22360

75. Betts MJ, Cardenas-Blanco A, Kanowski M, Jessen F, Düzel E (2017) In vivo MRI assessment of the human locus coeruleus along its rostrocaudal extent in young and older adults. Neuroimage 163:150-159 https://doi.org/10.101 6/j.neuroimage.2017.09.042

76. Acosta-Cabronero J, Betts MJ, Cardenas-Blanco A, Yang S, Nestor PJ (2016) In vivo MRI mapping of brain iron deposition across the adult lifespan. J Neurosci 36:364-374 https://doi.org/10.1523/JNEUROSCl.1907-15.2016

77. Acosta-Cabronero J, Williams GB, Cardenas-Blanco A, Arnold RJ, Lupson V, Nestor PJ (2013) In vivo quantitative susceptibility mapping (QSM) in Alzheimer's disease. PLoS One 8:e81093 https://doi.org/10.1371/journal. pone.0081093

78. van Bergen JMG, Li X, Quevenco FC et al (2018) Simultaneous quantitative susceptibility mapping and Flutemetamol-PET suggests local correlation of iron and $\beta$-amyloid as an indicator of cognitive performance at high age. Neuroimage 174:308-316 https://doi.org/10.1016/j.neuroimage.2018.03.021

79. Ayton S, Fazlollahi A, Bourgeat P et al (2017) Cerebral quantitative susceptibility mapping predicts amyloid- $\beta$-related cognitive decline. Brain 140:2112-2119 https://doi.org/10.1093/brain/awx137

80. Bechten A, Wattjes MP, Purcell DD et al (2017) Validation of an MRI rating scale for amyloid-related imaging abnormalities. J Neuroimaging 27:318325 https://doi.org/10.1111/jon.12422

81. Brashear HR, Ketter N, Bogert J, Di J, Salloway SP, Sperling R (2018) Clinical evaluation of amyloid-related imaging abnormalities in bapineuzumab phase III studies. J Alzheimers Dis 66:1409-1424 https://doi.org/10.3233/JA D-180675

82. Heuer E, Jacobs J, Du R et al (2017) Amyloid-related imaging abnormalities in an aged squirrel monkey with cerebral amyloid angiopathy. J Alzheimers Dis 57:519-530 https://doi.org/10.3233/JAD-160981

83. Ketter N, Brashear HR, Bogert J et al (2017) Central review of amyloid-related imaging abnormalities in two phase III clinical trials of bapineuzumab in mild-to-moderate alzheimer's disease patients. J Alzheimers Dis 57:557-573 https://doi.org/10.3233/JAD-160216

84. Martens RM, Bechten A, Ingala S et al (2018) The value of subtraction MRI in detection of amyloid-related imaging abnormalities with oedema or effusion in Alzheimer's patients: an interobserver study. Eur Radiol 28:12151226 https://doi.org/10.1007/s00330-017-5022-6 
85. Péran P, Cherubini A, Assogna F et al (2010) Magnetic resonance imaging markers of Parkinson's disease nigrostriatal signature. Brain 133:3423-3433 https://doi.org/10.1093/brain/awq212

86. Hutchinson M, Raff U, Lebedev S (2003) MRI correlates of pathology in parkinsonism: segmented inversion recovery ratio imaging (SIRRIM). Neuroimage 20:1899-1902 https://doi.org/10.1016/j.neuroimage.2003.07.012

87. Martin WRW, Wieler M, Gee M (2008) Midbrain iron content in early Parkinson disease: a potential biomarker of disease status. Neurology 70 1411-1417 https://doi.org/10.1212/01.wnl.0000286384.31050.b5

88. Ordidge RJ, Gorell JM, Deniau JC, Knight RA, Helpern JA (1994) Assessment of relative brain iron concentrations using T2-weighted and $T 2^{*}$-weighted MRI at 3 Tesla. Magn Reson Med 32:335-341 https://doi.org/10.1002/mrm.1 910320309

89. Vaillancourt DE, Prodoehl J, Abraham I et al (2009) High-resolution diffusion tensor imaging in the substantia nigra of de novo Parkinson disease. Neurology 72:1378-1384 https://doi.org/10.1212/01.wnl.0000340982.01727. $6 e$

90. Lehéricy S, Sharman MA, Dos Santos CL et al (2012) Magnetic resonance imaging of the substantia nigra in Parkinson's disease. Mov Disord 27:822830 https://doi.org/10.1002/mds.25015

91. Hirata FCC, Sato JR, Vieira G et al (2017) Substantia nigra fractional anisotropy is not a diagnostic biomarker of Parkinson's disease: a diagnostic performance study and meta-analysis. Eur Radiol 27:2640-2648 https://doi. org/10.1007/s00330-016-4611-0

92. Sclocco R, Beissner F, Bianciardi M, Polimeni JR, Napadow V (2018) Challenges and opportunities for brainstem neuroimaging with ultrahigh field MRI. Neuroimage 168:412-426 https://doi.org/10.1016/j.neuroimage.2 017.02.052

93. Balchandani P, Naidich TP (2015) Ultra-high-field MR neuroimaging. AJNR Am J Neuroradiol 36:1204-1215 https://doi.org/10.3174/ajnr.A4180

94. Deistung A, Schäfer A, Schweser F et al (2013) High-resolution MR imaging of the human brainstem in vivo at 7 Tesla. Front Hum Neurosci 7:710 https://doi.org/10.3389/fnhum.2013.00710

95. Cosottini M, Frosini D, Pesaresi I et al (2014) MR imaging of the substantia nigra at 7 T enables diagnosis of Parkinson disease. Radiology 271:831-838 https://doi.org/10.1148/radiol.14131448

96. Blazejewska Al, Schwarz ST, Pitiot A et al (2013) Visualization of nigrosome 1 and its loss in PD: pathoanatomical correlation and in vivo $7 \mathrm{~T} \mathrm{MRL}$ Neurology 81:534-540 https://doi.org/10.1212/WNL.0b013e31829e6fd2

97. Kwon D-H, Kim J-M, Oh S-H et al (2012) Seven-tesla magnetic resonance images of the substantia nigra in Parkinson disease. Ann Neurol 71:267-277 https://doi.org/10.1002/ana.22592

98. Damier P, Hirsch EC, Agid Y, Graybiel AM (1999) The substantia nigra of the human brain. Brain 122:1421-1436 https://doi.org/10.1093/brain/122.8.1421

99. Kim J-M, Jeong H-J, Bae YJ et al (2016) Loss of substantia nigra hyperintensity on 7 Tesla MRI of Parkinson's disease, multiple system atrophy, and progressive supranuclear palsy. Parkinsonism Relat Disord 26: 47-54 https://doi.org/10.1016/j.parkreldis.2016.01.023

100. Schwarz ST, Afzal M, Morgan PS, Bajaj N, Gowland PA, Auer DP (2014) The "swallow tail" appearance of the healthy nigrosome - a new accurate test of Parkinson's disease: a case-control and retrospective cross-sectional MRI study at 3 T. PLoS One 9:e93814 https://doi.org/10.1371/journal.pone.0093 814

101. Schmidt MA, Engelhorn T, Marxreiter F et al (2017) Ultra high-field SWI of the substantia nigra at $7 \mathrm{~T}$ : Reliability and consistency of the swallow-tail sign. BMC Neurol 17:194 https://doi.org/10.1186/s12883-017-0975-2

102. Damier P, Hirsch EC, Agid Y, Graybiel AM (1999) The substantia nigra of the human brain. Brain 122:1437-1448 https://doi.org/10.1093/brain/122.8.1437

103. Gramsch C, Reuter I, Kraff O et al (2017) Nigrosome 1 visibility at susceptibility weighted $7 \mathrm{~T} \mathrm{MRI}$ —A dependable diagnostic marker for Parkinson's disease or merely an inconsistent, age-dependent imaging finding? PLoS One 12: e0185489 https://doi.org/10.1371/journal.pone.0185489

104. Duguid JR, De La Paz R, DeGroot J (1986) Magnetic resonance imaging of the midbrain in Parkinson's disease. Ann Neurol 20:744-747 https://doi. org/10.1002/ana.410200618

105. Massey L, Miranda M, Al-Helli O et al (2017) 9.4 T MR microscopy of the substantia nigra with pathological validation in controls and disease. Neurolmage Clin 13:154-163 https://doi.org/10.1016/j.nicl.2016.11.015

106. Noh Y, Sung YH, Lee J, Kim EY (2015) Nigrosome 1 detection at 3 T MRI for the diagnosis of early-stage idiopathic Parkinson disease: assessment of diagnostic accuracy and agreement on imaging asymmetry and clinical laterality. AJNR Am J Neuroradiol 36:2010-2016 https://doi.org/10.3174/a jnr.A4412

107. Lehericy S, Vaillancourt DE, Seppi K et al (2017) The role of high-field magnetic resonance imaging in parkinsonian disorders: pushing the boundaries forward. Mov Disord 32:510-525 https://doi.org/10.1002/mds.2 6968

108. Cosottini M, Frosini D, Pesaresi I et al (2015) Comparison of $3 \mathrm{~T}$ and $7 \mathrm{~T}$ susceptibility-weighted angiography of the substantia nigra in diagnosing Parkinson disease. AJNR Am J Neuroradiol 36:461-466 https://doi.org/10.31 74/ajnr.A4158

109. Lotfipour AK, Wharton S, Schwarz ST et al (2012) High resolution magnetic susceptibility mapping of the substantia nigra in Parkinson's disease. J Magn Reson Imaging 35:48-55 https://doi.org/10.1002/jmri.22752

110. Bae YJ, Kim J-M, Kim E et al (2016) Loss of nigral hyperintensity on 3 Tesla MRI of Parkinsonism: comparison with ${ }^{123}$ I-FP-CIT SPECT. Mov Disord 31: 684-692 https://doi.org/10.1002/mds.26584

111. Schwarz ST, Mougin O, Xing Y et al (2018) Parkinson's disease related signal change in the nigrosomes $1-5$ and the substantia nigra using $T_{2}^{*}$ weighted 7 T MRI. Neuroimage Clin 19:683-689 https://doi.org/10.1016/j.nicl.2018.05. 027

112. Ceravolo R, Antonini A, Frosini D et al (2015) Nigral anatomy and striatal denervation in genetic Parkinsonism: a family report. Mov Disord 30:11481149 https://doi.org/10.1002/mds.26255

113. Frosini D, Cosottini M, Donatelli $G$ et al (2017) Seven tesla MRI of the substantia nigra in patients with rapid eye movement sleep behavior disorder. Parkinsonism Relat Disord 43:105-109 https://doi.org/10.1016/j.pa rkreldis.2017.08.002

114. Barber TR, Griffanti L, Bradley KM et al (2020) Nigrosome 1 imaging in REM sleep behavior disorder and its association with dopaminergic decline. Ann Clin Transl Neurol 7:26-35 https://doi.org/10.1002/acn3.50962

115. Sung YH, Noh Y, Lee J, Kim EY (2016) Drug-induced Parkinsonism versus idiopathic Parkinson disease: utility of Nigrosome 1 with 3-T Imaging. Radiology 279:849-858 https://doi.org/10.1148/radiol.2015151466

116. Perez Akly MS, Stefani CV, Ciancaglini L et al (2019) Accuracy of nigrosome1 detection to discriminate patients with Parkinson's disease and essential tremor. Neuroradiol J 32:395-400 https://doi.org/10.1177/1971400919853787

117. Tolosa E, Wenning G, Poewe W (2006) The diagnosis of Parkinson's disease. Lancet Neurol 5:75-86 https://doi.org/10.1016/S1474-4422(05)70285-4

118. Munoz E, Iranzo A, Rauek S et al (2011) Subclinical nigrostriatal dopaminergic denervation in the cerebellar subtype of multiple system atrophy (MSA-C). J Neurol 258:2248-2253 https://doi.org/10.1007/s00415011-6108-8

119. Cilia R, Rossi C, Frosini D et al (2011) Dopamine transporter SPECT imaging in Corticobasal Syndrome. PLoS One 6:e18301 https://doi.org/10.1371/ journal.pone.0018301

120. Frosini D, Ceravolo R, Tosetti M, Bonuccelli U, Cosottini M (2016) Nigral involvement in atypical parkinsonisms: evidence from a pilot study with ultra-high field MRI. J Neural Transm 123:509-513 https://doi.org/10.1007/ s00702-016-1529-2

121. Fearnley JM, Lees AJ (1991) Ageing and Parkinson's disease: substantia nigra regional selectivity. Brain 114:2283-2301 https://doi.org/10.1093/brain/114. 5.2283

122. Pavese N, Tai YF (2018) Nigrosome imaging and neuromelanin sensitive MR in diagnostic evaluation of Parkinsonism. Mov Disord Clin Pract 5:131-140 https://doi.org/10.1002/mdc3.12590

123. Zarow C, Lyness SA, Mortimer JA, Chui HC (2003) Neuronal loss is greater in the locus coeruleus than nucleus basalis and substantia nigra in Alzheimer and Parkinson diseases. Arch Neurol 60:337-341 https://doi.org/10.1001/a rchneur.60.3.337

124. Gesi M, Soldani P, Giorgi FS, Santinami A, Bonaccorsi I, Fornai F (2000) The role of the locus coeruleus in the development of Parkinson's disease. Neurosci Biobehav Rev 24:655-668 https://doi.org/10.1016/S0149-7634 (00)00028-2

125. Ohtsuka C, Sasaki M, Konno K et al (2013) Changes in substantia nigra and locus coeruleus in patients with early-stage Parkinson's disease using neuromelanin-sensitive MR imaging. Neurosci Lett 541:93-98 https://doi. org/10.1016/j.neulet.2013.02.012

126. Sasaki M, Shibata E, Tohyama K et al (2006) Neuromelanin magnetic resonance imaging of locus ceruleus and substantia nigra in Parkinson's disease. Neuroreport 17:1215-1218 https://doi.org/10.1097/01.wnr.000022 7984.84927.a7 
127. Tona K-D, van Osch MJP, Nieuwenhuis S, Keuken MC (2019) Quantifying the contrast of the human locus coeruleus in vivo at 7 Tesla MRI. PLoS One 14: e0209842 https://doi.org/10.1371/journal.pone.0209842

128. Ye R, O'Callaghan C, Rua C et al (2019) Imaging the locus coeruleus in Parkinson's disease with ultra-high 7 T MRI. In: Annual Meeting of the Organization for Human Brain Mapping, p W272

129. Tkáč I, Gruetter R (2005) Methodology of 1 H NMR spectroscopy of the human brain at very high magnetic fields. Appl Magn Reson 29:139-157 https://doi.org/10.1007/BF03166960

130. Emir UE, Auerbach EJ, Van De Moortele P-F et al (2012) Regional neurochemical profiles in the human brain measured by $1 \mathrm{H}$ MRS at $7 \mathrm{~T}$ using local B1 shimming. NMR Biomed 25:152-160 https://doi.org/10.1002/nbm.1727

131. Watanabe $H$, Fukatsu $H$, Katsuno $M$ et al (2004) Multiple regional $1 \mathrm{H}-\mathrm{MR}$ spectroscopy in multiple system atrophy: NAA/Cr reduction in pontine base as a valuable diagnostic marker. J Neurol Neurosurg Psychiatry 75:103-109

132. Emir UE, Tuite PJ, Öz G (2012) Elevated pontine and putamenal gaba levels in mild-moderate parkinson disease detected by 7 tesla proton mrs. PLoS One 7:e30918 https://doi.org/10.1371/journal.pone.0030918

133. Braak H, Del Tredici K, Rüb U et al (2003) Staging of brain pathology related to sporadic Parkinson's disease. Neurobiol Aging 24:197-211 https://doi. org/10.1016/S0197-4580(02)00065-9

134. Abosch A, Yacoub E, Ugurbil K, Harel N (2010) An assessment of current brain targets for deep brain stimulation surgery with susceptibility-weighted imaging at 7 Tesla. Neurosurgery 67:1745-1756 https://doi.org/10.1227/NEU. Ob013e3181f74105

135. Duchin Y, Abosch A, Yacoub E, Sapiro G, Harel N (2012) Feasibility of using ultra-high field (7 T) MRI for clinical surgical targeting. PLoS One 7:e37328 https://doi.org/10.1371/journal.pone.0037328

136. Patriat R, Cooper SE, Duchin Y et al (2018) Individualized tractography-based parcellation of the globus pallidus pars interna using $7 \mathrm{~T} \mathrm{MRI} \mathrm{in} \mathrm{movement}$ disorder patients prior to DBS surgery. Neuroimage 178:198-209 https://doi. org/10.1016/j.Neuroimage.2018.05.048

137. Shamir RR, Duchin Y, Kim J et al (2019) Microelectrode recordings validate the clinical visualization of subthalamic-nucleus based on $7 \mathrm{~T}$ magnetic resonance imaging and machine learning for deep brain stimulation surgery. Neurosurgery 84:749-757 https://doi.org/10.1093/neuros/nyy212

138. Chiò A, Calvo A, Moglia C et al (2011) Phenotypic heterogeneity of amyotrophic lateral sclerosis: a population based study. J Neurol Neurosurg Psychiatry 82:740-746 https://doi.org/10.1136/jnnp.2010.235952

139. Kiernan MC, Vucic S, Cheah BC et al (2011) Amyotrophic lateral sclerosis. Lancet 377:942-955 https://doi.org/10.1016/S0140-6736(10)61156-7

140. Montuschi A, lazzolino B, Calvo A et al (2015) Cognitive correlates in amyotrophic lateral sclerosis: a population-based study in Italy. J Neurol Neurosurg Psychiatry 86:168-173 https://doi.org/10.1136/jnnp-2013-307223

141. Riancho J, Bosque-Varela P, Perez-Pereda S, Povedano M, de Munaín AL, Santurtun A (2018) The increasing importance of environmental conditions in amyotrophic lateral sclerosis. Int J Biometeorol 62:1361-1374 https://doi. org/10.1007/s00484-018-1550-2

142. Corcia P, Tauber C, Vercoullie J et al (2012) Molecular imaging of microglial activation in amyotrophic lateral sclerosis. PLoS One 7:e52941 https://doi. org/10.1371/journal.pone.0052941

143. Turner MR, Bowser R, Bruijn L et al (2013) Mechanisms, models and biomarkers in amyotrophic lateral sclerosis. Amyotroph Lateral Scler Front Degener 14:19-32 https://doi.org/10.3109/21678421.2013.778554

144. Liu J, Wang F (2017) Role of neuroinflammation in amyotrophic lateral sclerosis: cellular mechanisms and therapeutic implications. Front Immunol 8:1005 https://doi.org/10.3389/fimmu.2017.01005

145. Kawamata T, Akiyama H, Yamada T, McGeer PL (1992) Immunologic reactions in amyotrophic lateral sclerosis brain and spinal cord tissue. Am J Pathol 140:691-707

146. Wijesekera LC, Leigh PN (2009) Amyotrophic lateral sclerosis. Orphanet J Rare Dis 4:3 https://doi.org/10.1186/1750-1172-4-3

147. Filippi M, Agosta F, Abrahams S et al (2010) EFNS guidelines on the use of neuroimaging in the management of motor neuron diseases. Eur J Neurol 17:526-e20 https://doi.org/10.1111/j.1468-1331.2010.02951.x

148. Atkinson AJ, Colburn WA, DeGruttola VG et al (2001) Biomarkers and surrogate endpoints: preferred definitions and conceptual framework. Clin Pharmacol Ther 69:89-95 https://doi.org/10.1067/mcp.2001.113989

149. Agosta F, Spinelli EG, Filippi M (2018) Neuroimaging in amyotrophic lateral sclerosis: current and emerging uses. Expert Rev Neurother 18:395-406 https://doi.org/10.1080/14737175.2018.1463160
150. Cosottini M, Donatelli G, Costagli M et al (2016) High-resolution 7 T MR imaging of the motor cortex in amyotrophic lateral sclerosis. AJNR Am J Neuroradiol 37:455-461 https://doi.org/10.3174/ajnr.A4562

151. Oba H, Araki T, Ohtomo K et al (1993) Amyotrophic lateral sclerosis: T2 shortening in motor cortex at MR imaging. Radiology 189:843-846 https:// doi.org/10.1148/radiology.189.3.8234713

152. Ishikawa K, Nagura H, Yokota T, Yamanouchi H (1993) Signal loss in the motor cortex on magnetic resonance images in amyotrophic lateral sclerosis. Ann Neurol 33:218-222 https://doi.org/10.1002/ana.410330214

153. Ignjatović A, Stević Z, Lavrnić S, Daković M, Bačić G (2013) Brain iron MRl: a biomarker for amyotrophic lateral sclerosis. J Magn Reson Imaging 38:14721479 https://doi.org/10.1002/jmri.24121

154. Adachi Y, Sato N, Saito $Y$ et al (2015) Usefulness of SWI for the detection of iron in the motor cortex in amyotrophic lateral sclerosis. J Neuroimaging 25 443-451 https://doi.org/10.1111/jon.12127

155. Donatelli G, Retico A, lenco EC et al (2018) Semiautomated evaluation of the primary motor cortex in patients with amyotrophic lateral sclerosis at 3 T. AJNR Am J Neuroradiol 39:63-69 https://doi.org/10.3174/ajnr.A5423

156. Obusez EC, Lowe M, Oh SH et al (2018) 7 T MR of intracranial pathology: preliminary observations and comparisons to $3 \mathrm{~T}$ and 1.5T. Neuroimage 168: 459-476 https://doi.org/10.1016/j.Neuroimage.2016.11.030

157. Fukunaga M, Li TQ, Van Gelderen P et al (2010) Layer-specific variation of iron content in cerebral cortex as a source of MRI contrast. Proc Natl Acad Sci U S A 107:3834-3839 https://doi.org/10.1073/pnas.0911177107

158. Costagli M, Donatelli G, Biagi L et al (2016) Magnetic susceptibility in the deep layers of the primary motor cortex in amyotrophic lateral sclerosis. Neuroimage Clin 12:965-969 https://doi.org/10.1016/j.nicl.2016.04.011

159. Pallebage-Gamarallage M, Foxley S, Menke RAL et al (2018) Dissecting the pathobiology of altered MRI signal in amyotrophic lateral sclerosis: a post mortem whole brain sampling strategy for the integration of ultra-high-field MRI and quantitative neuropathology. BMC Neurosci 19:1-24 https://doi. org/10.1186/s12868-018-0416-1

160. Schweitzer AD, Liu T, Gupta A et al (2015) Quantitative susceptibility mapping of the motor cortex in amyotrophic lateral sclerosis and primary lateral sclerosis. AJR Am J Roentgenol 204:1086-1092 https://doi.org/1 $0.2214 /$ AJR.14.13459

161. Walhout R, Westeneng HJ, Verstraete E et al (2015) Cortical thickness in ALS: towards a marker for upper motor neuron involvement. J Neurol Neurosurg Psychiatry 86:288-294 https://doi.org/10.1136/jnnp-2013-306839

162. Acosta-Cabronero J, Machts J, Schreiber S et al (2018) Quantitative susceptibility MRI to detect brain iron in amyotrophic lateral sclerosis. Radiology 289:195-203 https://doi.org/10.1148/radiol.2018180112

163. Donatelli G, Caldarazzo lenco E, Costagli M et al (2019) MRI cortical feature of bulbar impairment in patients with amyotrophic lateral sclerosis. Neuroimage Clin 24:101934 https://doi.org/10.1016/j.nicl.2019.101934

164. Tkáč I, Öz G, Adriany G, Uğurbil K, Gruetter R (2009) In vivo 1H NMR spectroscopy of the human brain at high magnetic fields: Metabolite quantification at 4T vs. 7 T. Magn Reson Med 62:868-879 https://doi.org/1 $0.1002 / \mathrm{mrm} .22086$

165. Ebisu T, Rooney WD, Graham SH, Weiner MW, Maudsley AA (1994) Nacetylaspartate as an in vivo marker of neuronal viability in kainate- induced status epilepticus: $1 \mathrm{H}$ magnetic resonance spectroscopic imaging. J Cereb Blood Flow Metab 14:373-382 https://doi.org/10.1038/jcbfm.1994.48

166. Brand A, Richter-Landsberg C, Leibfritz D (1993) Multinuclear NMR studies on the energy metabolism of glial and neuronal cells. Dev Neurosci 15:289298 https://doi.org/10.1159/000111347

167. Atassi N, Xu M, Triantafyllou C et al (2017) Ultra high-field (7 Tesla) magnetic resonance spectroscopy in Amyotrophic Lateral Sclerosis. PLoS One 12: e0177680 https://doi.org/10.1371/journal.pone.0177680

168. Cheong I, Marjańska M, Deelchand DK, Eberly LE, Walk D, Öz G (2017) Ultrahigh field proton MR spectroscopy in early-stage amyotrophic lateral sclerosis. Neurochem Res 42:1833-1844 https://doi.org/10.1007/s11064-01 7-2248-2

169. Doble A (1996) The pharmacology and mechanism of action of riluzole. Neurology 47:233S-241S https://doi.org/10.1212/WNL.47.6_Suppl_4.233S

170. Mantz J, Laudenbach V, Lecharny JB, Henzel D, Desmonts JM (1994) Riluzole, a novel antiglutamate, blocks GABA uptake by striatal synaptosomes. Eur J Pharmacol 257:R7-R8 https://doi.org/10.1016/0014-2 999(94)90716-1

171. Danbolt NC (2001) Glutamate uptake. Prog Neurobiol 65:1-105 https://doi. org/10.1016/S0301-0082(00)00067-8 
172. Majounie E, Renton AE, Mok K et al (2012) Frequency of the C9orf72 hexanucleotide repeat expansion in patients with amyotrophic lateral sclerosis and frontotemporal dementia: a cross-sectional study. Lancet Neurol 11:323-330 https://doi.org/10.1016/S1474-4422(12)70043-1

173. DeJesus-Hernandez M, Mackenzie IR, Boeve BF et al (2011) Expanded GGGGCC hexanucleotide repeat in noncoding region of C9ORF72 causes chromosome 9p-linked FTD and ALS. Neuron 72:245-256 https://doi.org/1 0.1016/..neuron.2011.09.011

174. Westeneng $\mathrm{H}-\mathrm{J}$, Wismans $\mathrm{C}$, Nitert AD et al (2017) Metabolic differences between asymptomatic C9orf72 carriers and non-carriers assessed by brain 7 T MRSI. In: Annual Meeting of the International Society for Magnetic Resonance in Medicine, $\mathrm{p} 0028$

175. Donatelli G, Westeneng H-J, van Veenhuijzen K et al (2018) 31P MRSI of asymptomatic C9orf72 carriers and non-carriers at 7 Tesla. In: Joint Annual Meeting ISMRM-ESMRMB, p 0583

176. Agosta F, Chiò A, Cosottini M et al (2010) The present and the future of neuroimaging in amyotrophic lateral sclerosis. AJR Am J Neuroradiol 31: 1769-1777 https://doi.org/10.3174/ajnr.A2043

177. Verstraete E, Polders DL, Mandl RCW et al (2014) Multimodal tract-based analysis in ALS patients at $7 \mathrm{~T}$ : a specific white matter profile? Amyotroph Lateral Scler Front Degener 15:84-92 https://doi.org/10.3109/21678421.2013. 844168

178. Barry RL, Vannesjo SJ, By S, Gore JC, Smith SA (2018) Spinal cord MRI at 7 T. Neuroimage 168:437-451 https://doi.org/10.1016/j.Neuroimage.2017.07.003

179. Sigmund EE, Suero GA, Hu C et al (2012) High-resolution human cervical spinal cord imaging at 7 T. NMR Biomed 25:891-899 https://doi.org/10.1 002/nbm.1809

180. Henning A, Koning W, Fuchs A et al (2016) 1H MRS in the human spinal cord at $7 \mathrm{~T}$ using a dielectric waveguide transmitter, RF shimming and a high density receive array. NMR Biomed 29:1231-1239 https://doi.org/10.1 $002 / \mathrm{nbm} .3541$

181. Kogan F, Singh A, Debrosse C et al (2013) Imaging of glutamate in the spinal cord using GluCEST. Neuroimage 77:262-267 https://doi.org/10.1016/ j.Neurolmage.2013.03.072

182. Massire A, Rasoanandrianina H, Taso M et al (2018) Feasibility of single-shot multi-level multi-angle diffusion tensor imaging of the human cervical spinal cord at 7 T. Magn Reson Med 80:947-957 https://doi.org/10.1002/ mrm.27087

183. Cohen-Adad J, Zhao W, Keil B et al (2013) 7-T MRI of the spinal cord can detect lateral corticospinal tract abnormality in amyotrophic lateral sclerosis. Muscle Nerve 47:760-762 https://doi.org/10.1002/mus.23720

\section{Publisher's Note}

Springer Nature remains neutral with regard to jurisdictional claims in published maps and institutional affiliations.

\section{Submit your manuscript to a SpringerOpen ${ }^{\circ}$ journal and benefit from:}

- Convenient online submission

- Rigorous peer review

- Open access: articles freely available online

- High visibility within the field

- Retaining the copyright to your article

Submit your next manuscript at $\boldsymbol{\nabla}$ springeropen.com 